\title{
过渡金属催化联烯胺环化反应进展
}

\author{
耿佃国* \\ (淄博职业学院＼cjkstart淄博 255314)
}

\begin{abstract}
摘要 近年来, 具有独特反应性、选择性、易得性和稳定性的联烯胺类化合物受到化学工作者们的关注, 尤其是关于 联烯胺环化反应的报道与日俱增. 总结归纳了涉及过渡金属催化的联烯胺环化反应，主要分为钯、钓、铑、金、钴、 银、铂、镍八部分介绍, 并详细讨论了多数转化的反应机理.

关键词 联烯胺; 环化反应; 杂环化合物; 过渡金属催化
\end{abstract}

\section{Recent Advances on Transition-Metal-Catalyzed Allenamides Cyclization}

\author{
Geng, Dianguo* \\ (Zibo Vocational Institute, Zibo 255314)
}

\begin{abstract}
With the especial reactivity, selectivity, availability and stability, the allenamides have got more and more attention, and the reports on allenamides cyclization grow rapidly. This review gives an up-to-date overview of transition-metal-catalyzed allenamides cyclization, which are sorted by metal catalysts in eight categories of $\mathrm{Pd}, \mathrm{Ru}, \mathrm{Rh}, \mathrm{Au}, \mathrm{Co}, \mathrm{Ag}$, $\mathrm{Pt}$ and Ni. For most of these transformations, the plausible mechanisms are demonstrated in details. Clarification of these issues is the key point for understanding the transition-metal-catalyzed allenamides cyclization and developing new high performance methodologies for chemists.
\end{abstract}

Keywords allenamides; cyclization; heterocyclic compounds; transition metal catalysis

现代合成化学和精细化学品工业不仅为人类生活 提供了赖以生存的物质基础, 而且对于人工智能和航天 等高科技领域的飞速发展也具有重要的推动作用, 在医 药、农药、保健品、环保等行业表现的尤为突出. 近几 年, 随着世界医药产业的飞速发展, 合成新药物分子本 体的难度不断增大, 有机合成化学也面临着更大的机遇 和挑战, 发展新颖的合成方法学显得尤为重要.

化学合成的核心为化学键的构建, 而如何高效地构 建 $\mathrm{C}-\mathrm{X}$ 键 $(\mathrm{X}=\mathrm{C}, \mathrm{N}, \mathrm{O}, \mathrm{S}$, 卤素等)一直是有机化学界 关注的热点. 在过去的几十年中, 过渡金属催化的交叉 偶联反应已经发展成为化学键构建必不可少的工具 ${ }^{[1]}$, 同时, 提高合成效率、降低能耗、减少废物排放及发展 环境友好型化学更加符合当今的时代背景.

近四十年来, 有关联烯胺的研究逐渐增多, 日趋完 善, 联烯胺类化合物逐渐成为有机合成中的重要前驱体 和结构单元, 能在多种过渡金属的催化作用下反应, 尤 其是 $\pi$ 酸性的金属元素, 如 $\mathrm{Au} 、 \mathrm{Pd} 、 \mathrm{Ru} 、 \mathrm{Rh}$ 等, 这些
过渡金属催化剂能够与中心碳原子配位，产生活性中间 体, 发生偶联、环化等, 生成二烯、杂环类化合物。这类 反应大多呈现出反应条件温和、适用底物范围广等特点, 因此, 可以通过引入联烯胺的方式, 生成新的可作为亲 电、亲核试剂连续进攻的中间体，进一步转化实现 $\mathrm{C}-$ $\mathrm{X}$ 键的高效构建, 发展新的方法学.

自 1968 年第一例报道制备联烯胺以来, 联烯胺的 研究吸引了众多科研工作者的兴趣. 其中, 过渡金属催 化联烯胺环化, 合成特定的分子结构成为了联烯胺研究 中的主要内容, 包括钯催化、金催化、铑催化、钉催化 以及镍催化等. 相较于传统的催化反应体系, 过渡金属 催化反应具有效率更高、热稳定性以及化学稳定性更好, 催化循环寿命长等优点. 同时, 由于联烯胺其独特的反 应性, 选择性、易得性和稳定性, 已被广泛用于联烯胺 $[2+2],[3+2],[4+2],[2+2+2]$ 等加成环化和串联环化 反应中, 以构建四至九元碳环或杂环骨架. 在新型有机 反应的探索中, 过渡金属催化联烯胺环化反应丰富了含

* Corresponding author. E-mail: gengdianguo@126.com

Received July 17, 2018; revised September 6, 2018; published online September 26, 2018. 
氮、氧杂环合成方法学, 同时为有机化学发展应用奠定 了良好的基础. 本文根据金属催化剂进行分类，对联烯 胺环化反应进行了归纳和总结, 并对相应的反应机理 进行了讨论.

\section{$1 \mathrm{Pd}$ 催化联烯胺环化反应}

过渡金属钯催化剂具有性质稳定、活性表面积大、 原子经济性相对较高等特点, 被广泛地应用于天然产物 全合成等催化体系, 偶联反应高效构建目标分子骨架, 包括 $\mathrm{C}-\mathrm{C}$ 键、 $\mathrm{C}-\mathrm{X}$ 键等. 钯催化联烯胺环化过程的反 应机理大体可以概括为 Scheme 1 所示的反应途径, 主 要包括碳卤键对 $\operatorname{Pd}(0)$ 的氧化加成, 联烯胺插入并形成 $\pi$-烯丙基钯中间体, 最后以 $\beta$ - $\mathrm{H}$ 消除、亲核取代等淬灭 方式, 选择性地在 $\alpha$ 位或 $\gamma$ 位形成新的化学键.

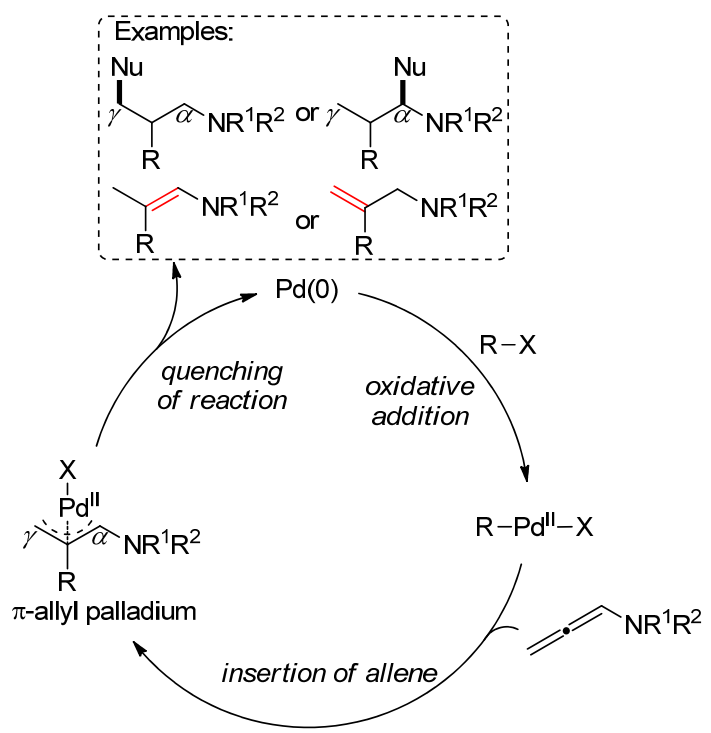

图式 1 钯催化联烯胺反应的主要步骤

Scheme 1 Main steps for Pd-catalyzed allenamides reaction

\section{$1.1 \mathrm{Pd}$ 催化联烯胺亲核取代环化反应}

1995 年, Grigg 课题组 ${ }^{[2]}$ 报道了第一例 Pd 催化的分
子内碳钯化/环化-阴离子捕获串联反应实现联烯胺分子 内的环化反应(Scheme 2). $\operatorname{Pd}(0)$ 启动该反应循环，最后 在碳酸钾存在的条件下，经还原消除得到 $\gamma$ 位取代的环 化产物. 若加入碳酸银, 中间体可能脱掉一分子 AgI, 形成钯阳离子中间体，更倾向于进攻 $\alpha$ 位，两种不同的 环化方式产率分别为 $91 \%$ 和 77\%.

Grigg 课题组 ${ }^{[3]}$ 随后对 Pd 催化联烯胺, 阴离子捕获 环化反应进行了进一步的探究, 并在 2001 年报道了一 例联烯胺环化反应(Scheme 3). 该转化经历相似的氧化 加成、环化、形成 $\pi$-烯丙基钯中间体 $\mathbf{8}$ 过程. 与之前工 作不同的是，本次报道是将亲核试剂引入联烯胺分子 内, 完成分子内 $\alpha$ 位的亲核进攻, 得到一系列多环异喹 啉酮的化合物.

2006 年, Grigg 课题组 ${ }^{[4]}$ 又报道了一例钯/铟双金属 催化的联烯胺环化反应. 机理如 Scheme 4 所示, 在该转 化中首先形成 $\pi$-烯丙基钯中间体，随后完成钯与铟的转 金属交换过程，再与手性叔丁基亚磺酰亚胺配位形成六 元椅式过渡态, 最后得到包含连续两个手性中心的化合 物 13 .

2005 年, Hiroya 课题组 ${ }^{[5]}$ 报道了一例钯催化联烯胺 与芳基碘化物的分子间环化反应(Scheme 5). 在反应过 程中，尽管存在取代基空间位阻的影响， $\mathrm{O}$ 或 $\mathrm{N}$ 等亲核 基团仍然优先对 $\alpha$ 位进攻，以 5-或 6-exo-trig 环化的方式 得到产物. 作者认为, 由于氮原子对邻位 $\alpha$ 碳的电性影 响, 使得 $\alpha$ 碳原子周围的电子云偏向于 $\mathrm{N}$ 原子, 相比于 $\gamma$ 位碳原子更加具有亲电性，因此亲核基团更倾向于进 攻烯丙基 $\alpha$ 位, 得到环化产物 16, 并没有得到 $\gamma$ 位碳原 子进攻环化产物 17 .

Savic 课题组 ${ }^{[6]}$ 在 2012 年也对该类型反应进行了相 关的探索，并进行了报道(Scheme 6). 作者以醋酸根阴 离子作为捕获剂，较好完成了分子间亲核取代的过程， 得到进攻 $\gamma$ 位的环化产物. 值得注意的是, 在作者试图 进行分子间一锅法实现联烯胺环化的探索中, 发现联烯 胺和 4-碘苯甲醚在相同的条件下反应并没有得到环化

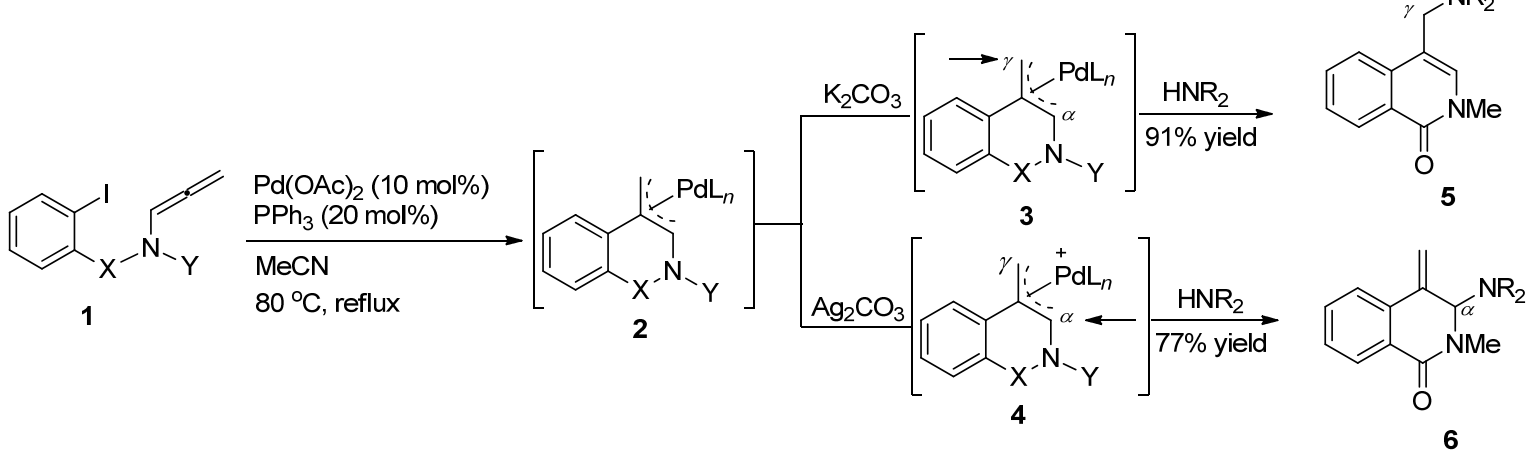

图式 2 钯催化联烯胺选择性环化

Scheme 2 Pd-catalyzed selective cyclization of allenamides 
<smiles>O=C(c1ccccc1I)N(Cc1ccccc1)Cc1ccccc1CO</smiles>

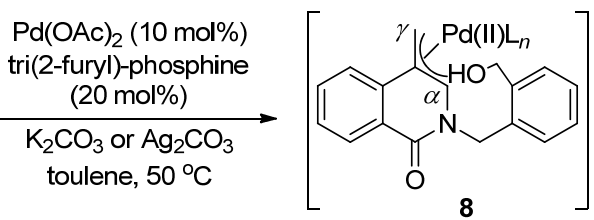
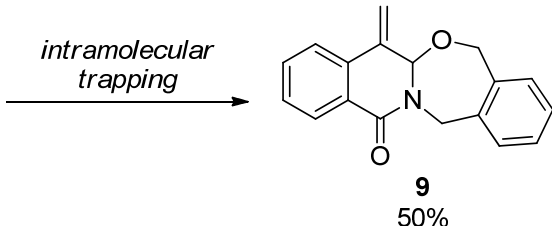

图式 3 钯催化联烯胺分子内亲核进攻环化

Scheme 3 Pd catalyzed the intramolecular nucleophilic offensive cyclization of allenamides

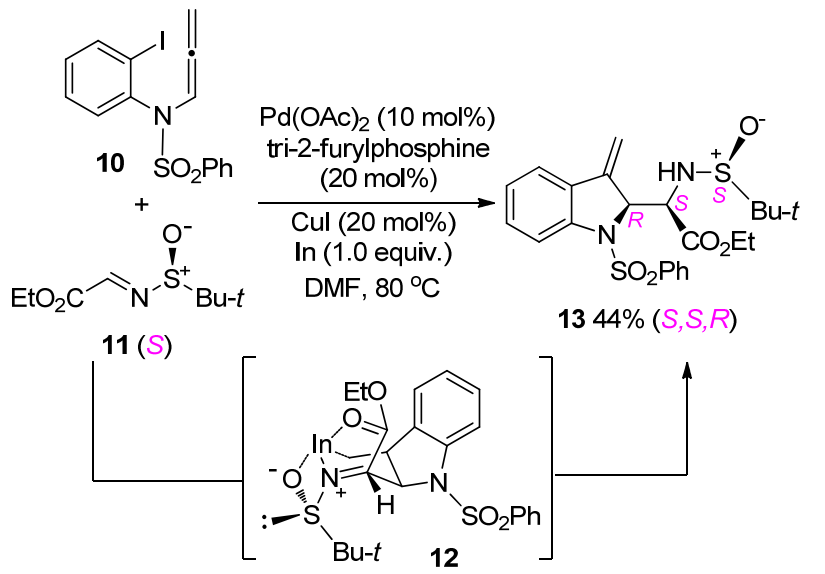

图式 4 钯-铟双金属催化的联烯胺环化反应

Scheme 4 Palladium/indium bimetallic catalyzed allenamides cyclization

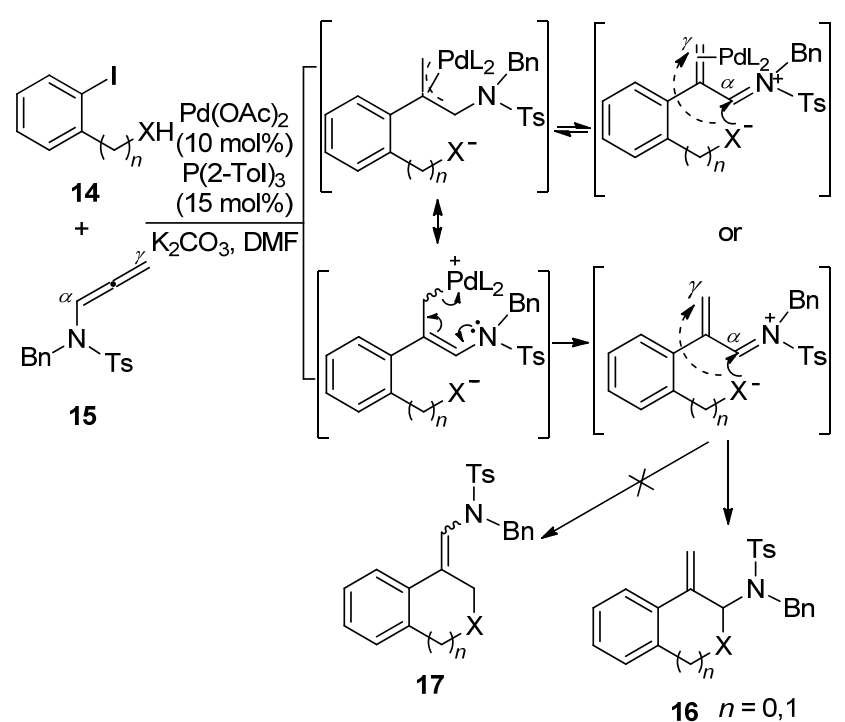

图式 5 钯催化联烯胺与芳基碘化物的分子间环化反应

Scheme 5 Pd-catalyzed intermolecular cyclization of allenamides with aryl iodides

的产物, 而是以 $29 \%$ 和 19\%的低产率得到联烯胺选择性 异构化的乙酸酯 22 和 23.

2014 年, 童晓峰课题组 ${ }^{[7]}$ 继续完成了钯催化联烯胺 分子内环化的工作 (Scheme 7), 作者以 $\mathrm{PdCl}_{2}\left(\mathrm{PPh}_{3}\right)_{2}$ 为催 化剂, 得到 $\pi$-烯丙基钯中间体 $\mathbf{2 5}$, 与 Grigg 等工作不同 之处在于, 作者构建的是烯基联烯胺, 而非芳基取代的

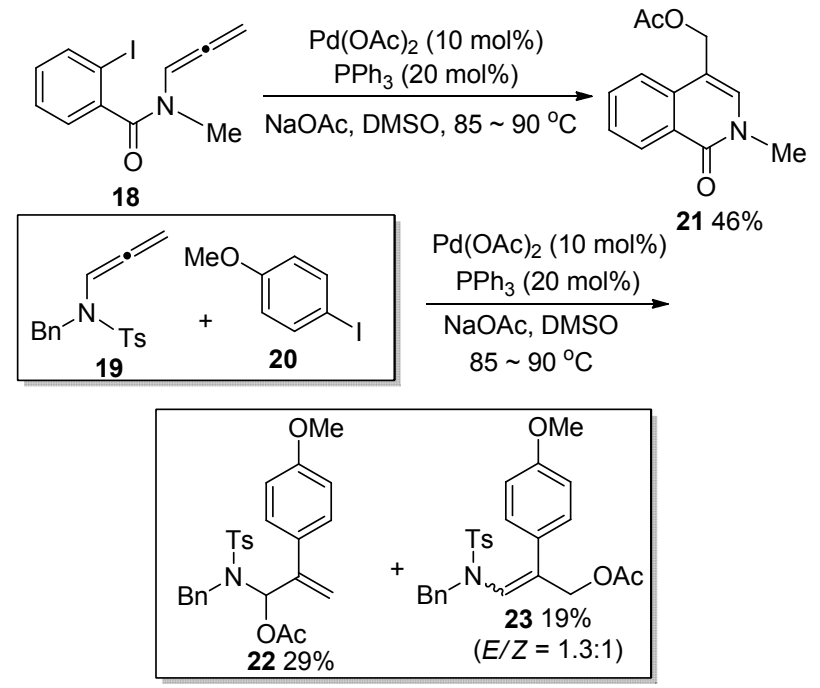

图式 6 钯催化联烯胺与芳基碘化物的选择性异构化反应 Scheme 6 Pd-catalyzed selective isomerization of allenamides with aryl iodides

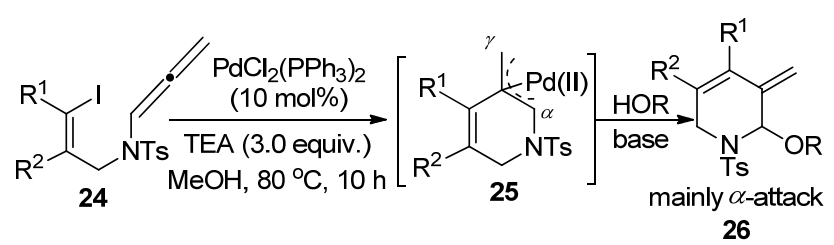

图式 7 钯催化联烯胺与醇之间的亲核进攻反应

Scheme 7 Pd-catalyzed cyclization of vinyl iodide-tethered allensulfonamides

联烯胺，随后以甲醇作为亲核试剂进攻 $\pi$-烯丙基钯中间 体 25, 得到进攻 $\alpha$ 位的环化产物 26.

2016 年, 刘会课题组 ${ }^{[8]}$ 实现了一例联烯胺与芳基碘 之间的环化-Heck 反应(Scheme 8). 该反应起始于 $\operatorname{Pd}(0)$ 对芳基碘的氧化加成，得到 $\pi$-烯丙基钯中间体，在实验 的探索和条件笁选阶段，作者并没有检测到联烯胺 $\alpha$ 位 碳选择性四元环化产物 31, 而是经过 6-exo 环化过程, 联烯胺 $\gamma$ 位碳原子选择性环化. 通过该转化可以得到一 系列 3-亚甲基-5-苯基-四氢吡啶类化合物 28, 该骨架结 构在治疗糖尿病、帕金森以及肥胖症等活性药物分子中 广泛存在. 同时, 烯基溴化物也能在该转化中表现出较 好的兼容性，得到分子内包含共轭二烯结构的产物 29 , 具有更广泛的潜在应用价值. 


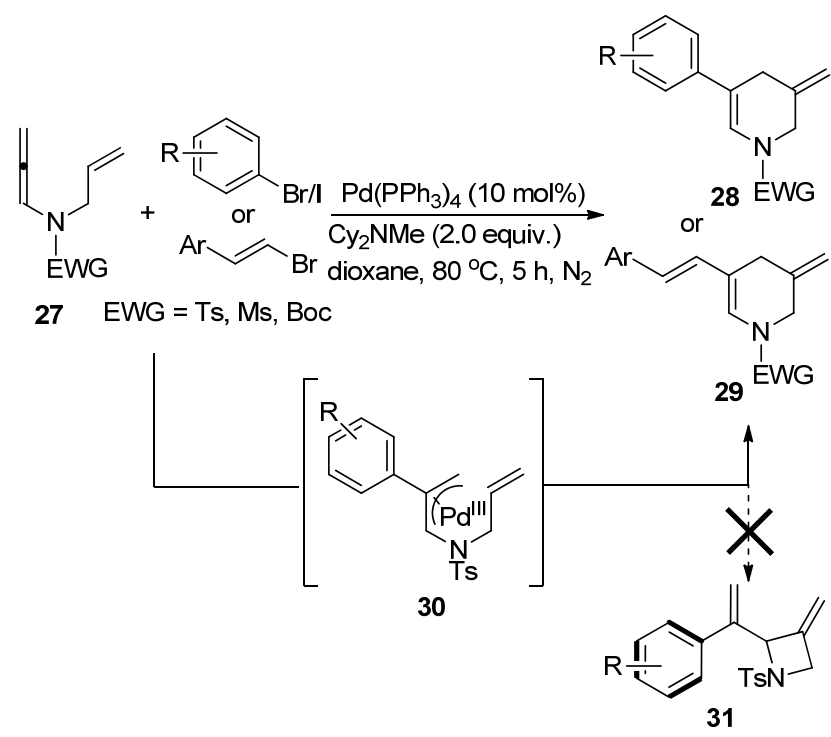

图式 8 钯催化联烯胺与芳基碘间环化 Heck 反应

Scheme 8 Pd-catalyzed cyclization-Heck of allenamides and aryl iodides

2010 年, Broggini 课题组 ${ }^{[9]}$ 报道了一例钯催化联烯 胺分子内的环加成反应(Scheme 9). 在微波条件下, Pd 与吲哚 $\mathrm{N}$ 原子配位生成 $\mathrm{H}-\mathrm{Pd}(\mathrm{II})$ 物种 35, 随后插入联烯 基团，形成 $\pi$-烯丙基钯中间体，最后还原消除得到环化 产物 33. 若加入芳基碘, 则首先钯与碳碘键氧化加成, 再对联烯胺插入形成 $\pi$-烯丙基把中间体 36, 随后硒原 子完成对吲哚 $\mathrm{N}$ 原子的亲核取代过程, 最后还原消除, 得到进攻 $\alpha$ 位产物 34 .

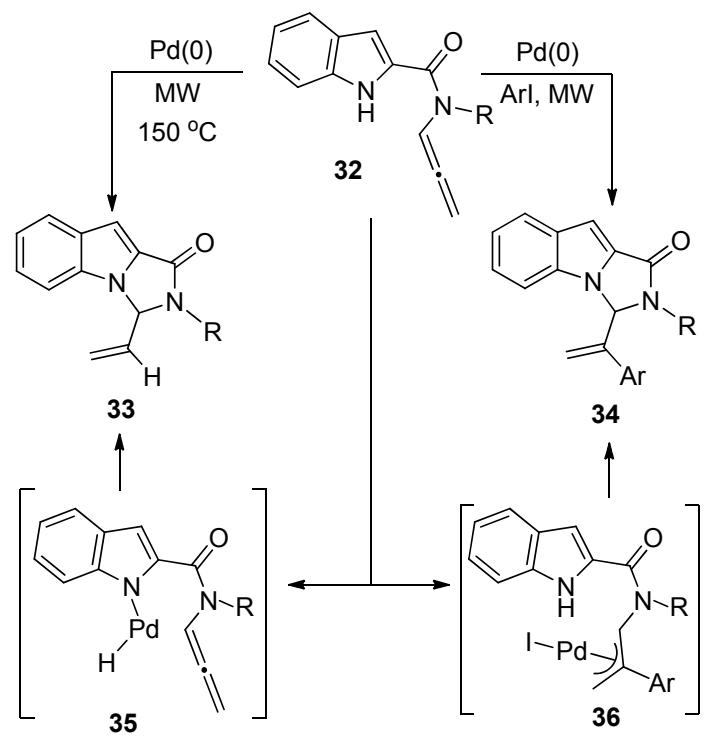

图式 9 钯催化联烯胺分子内的环加成反应 Scheme 9 Pd-catalyzed cycloaddition reaction of allenamines

\section{$1.2 \mathrm{Pd}$ 催化联烯胺 Diels-Alder 环化反应}

1996 年, Grigg 课题组 ${ }^{[10]}$ 报道了一例多组分间的高
区域和立体选择性 5-或 6-exo-dig 环化反应(Scheme 10). 首先，在 $\mathrm{Tl}_{2} \mathrm{CO}_{3}$ 存在的条件下，丙炔胺化合物 37 异构 得到联烯胺化合物 38. 随后在 Pd 的作用下完成碳卤键 的氧化加成、分子内环化等过程得到不稳定的化合物 39，该化合物虽未能分离得到，但能够被 $N$-马来酰亚胺 (NMM)捕获, 发生 Diels-Alder 偶联反应得到手性环化 产物 40 .

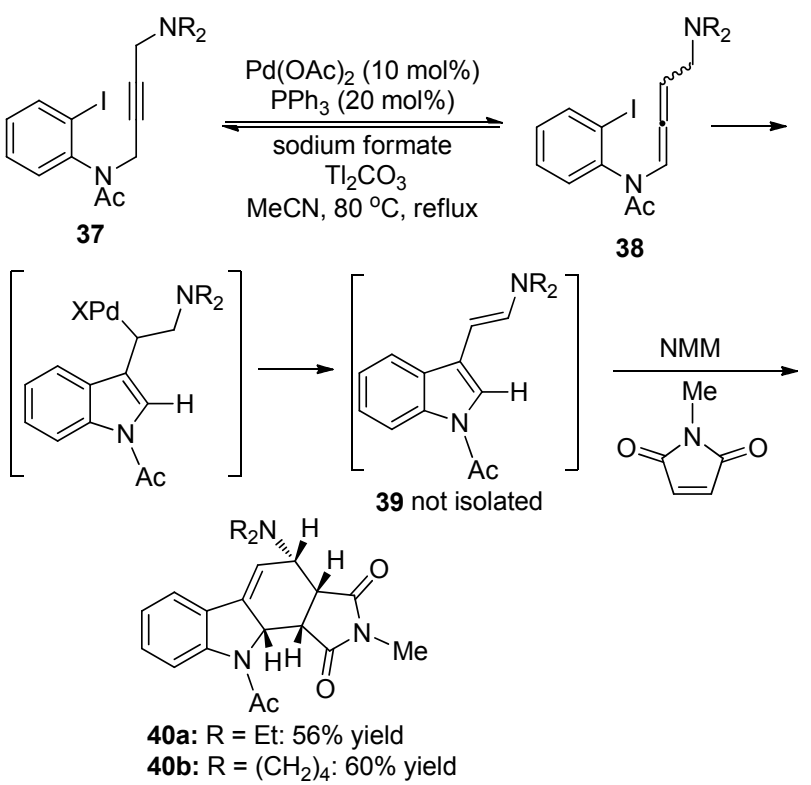

图式 10 钯催化联烯胺分子间 Diels-Alder 环加成反应 Scheme 10 Pd-catalyzed Diels-Alder cycloaddition of allenamides

当捕获剂为 $\mathrm{NaN}_{3}$ 时, 得到环化产物 42, 在丁炔二 酸二甲酯(DMAD)存在下, 可以得到 1,3-偶极环加成产 物 43. 而当降冰片二烯参与反应时，则会经历中间体 44, 发生 Diels-Alder 环加成反应，获得三唑化合物 $\mathbf{4 5}^{[11]}$ (Scheme 11).

基于同样的设计思路, Sasaki 课题组 ${ }^{[12]}$ 在 2007 年实 现了分子内联烯胺 Diels-Alder 加成环化得到 2,3 位取代 的吲哚衍生物(Scheme 12). 首先, Pd 对碳碘键氧化加成, 失去一分子 $\mathrm{AgI}$, 得到 Pd 阳离子中间体 46, 还原消除得 到吲哚-2,3-醌二甲烷 47. 在外部亲双烯体存在的情况 下，分子间发生 Diels-Alder 环加成反应，以较好的产率 得到四氢咔唑类化合物 48. 在没有外部亲双烯体存在 的情况下，两分子的 47 可以发生分子间 Diels-Alder 环 加成反应，分离出同型二聚体 49 和 50.

\section{$1.3 \mathrm{Pd}$ 催化联烯胺杂原子消除环化反应}

在 $P d$ 催化联烯胺环化的研究进展中, Grigg 课题 组 ${ }^{[13]}$ 在 1996 年报道了一例锡烷基化-碳钯化串联反应 构建含氮、氧杂环的反应(Scheme 13). 转化经历联烯胺 $\alpha$ 位碳原子区域选择性环化, 得到中环 $(5 \sim 7)$ 和大环 


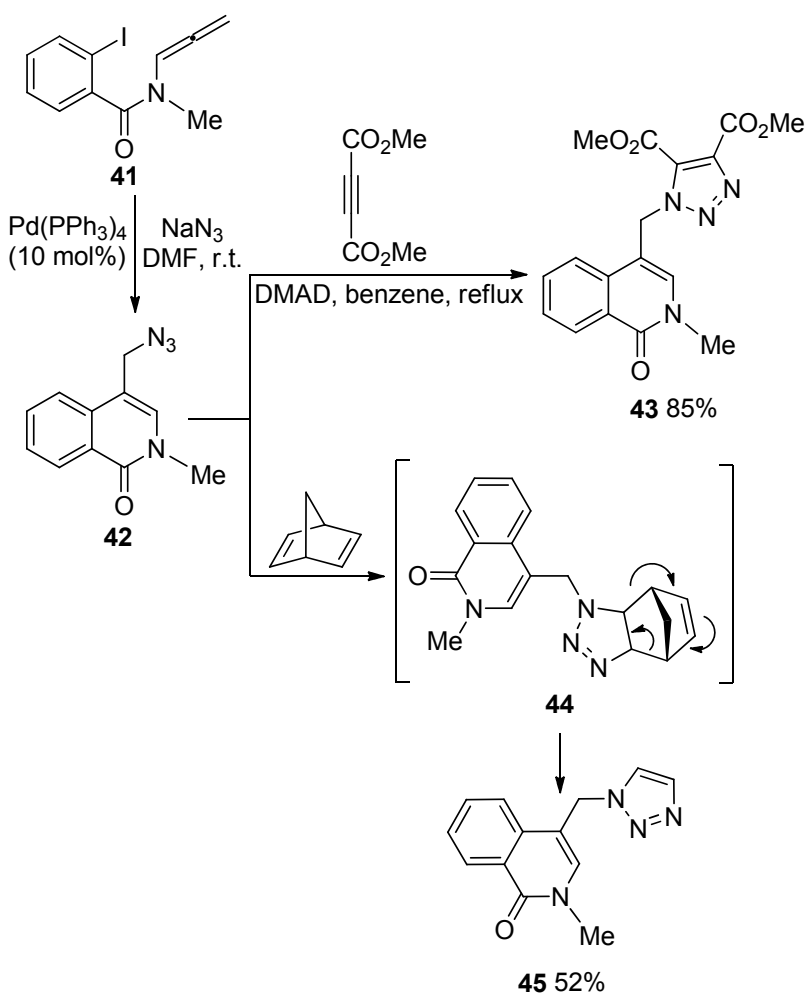

图式 11 钯催化联烯胺与降冰片二烯 Diels-Alder 反应 Scheme 11 Pd-catalyzed Diels-Alder cycloaddition of allenamides and 2,5-norbornadiene

$(7 \sim 11)$ 类型的杂环化合物. 反应由 $\operatorname{Pd}(0)$ 启动, 首先对 碳卤键氧化加成, 经碳钯化、环化、还原消除等过程, 最 终再生 $\operatorname{Pd}(0)$ 催化剂完成催化循化. 在中间体 $\mathbf{5 4}$ 环化的 过程中, $n-\mathrm{Bu}_{3} \mathrm{SnPdX}$ 的消除速度高于 $\beta-\mathrm{H}$ 的消除速度, 以较理想的产率得到最终环化产物 55.

2006 年, Cheng 课题组 ${ }^{[14]}$ 报道了一例新型 Pd 催化联 烯胺环化反应(Scheme 14). 反应起始于 $\operatorname{Pd}(0)$ 对烯基碘 的氧化加成, 随后得到 $\pi$-烯丙基钯中间体 $\mathbf{5 7}$, 与 58 的 双键配位得到中间体 $\mathbf{5 9}$, 随后经过迁移插入和 $\beta$-氧同 步消除产生钯一氧络合物 60 . 在锌的作用下发生 Pd 转移 过程, 再生 $\operatorname{Pd}(0)$ 催化剂, 中间体 $\mathbf{6 1}$ 经水解处理后, 最 终得到 1,2-二氢异喹啉甲基-1,2-二氢-1-䒺酚衍生物.

\section{$1.4 P d$ 催化联烯胺 Suzuki-Miyaura 偶联环化反应}

2012 年, 当 Lai 课题组 ${ }^{[15]}$ 试图通过 Suzuki-Miyaura 偶联构建四取代的联烯胺化合物时, 发现并没有获得偶 联产物. 作者认为, 联烯胺 63 可能以中间体的形式存 在, 通过分子内环化, 得到六元含氧化合物 64 (Scheme 15).

Grigg 等 ${ }^{[16]}$ 在 1997 年报道了一例 Pd 催化 SuzukiMiyaura 偶联环化反应(Scheme 16). 与之前描述的机理 非常相似, 该反应首先也是经历氧化加成、环化形成烯 丙基中间体 66. 接着中间体 66 与芳基硼酸完成转金属

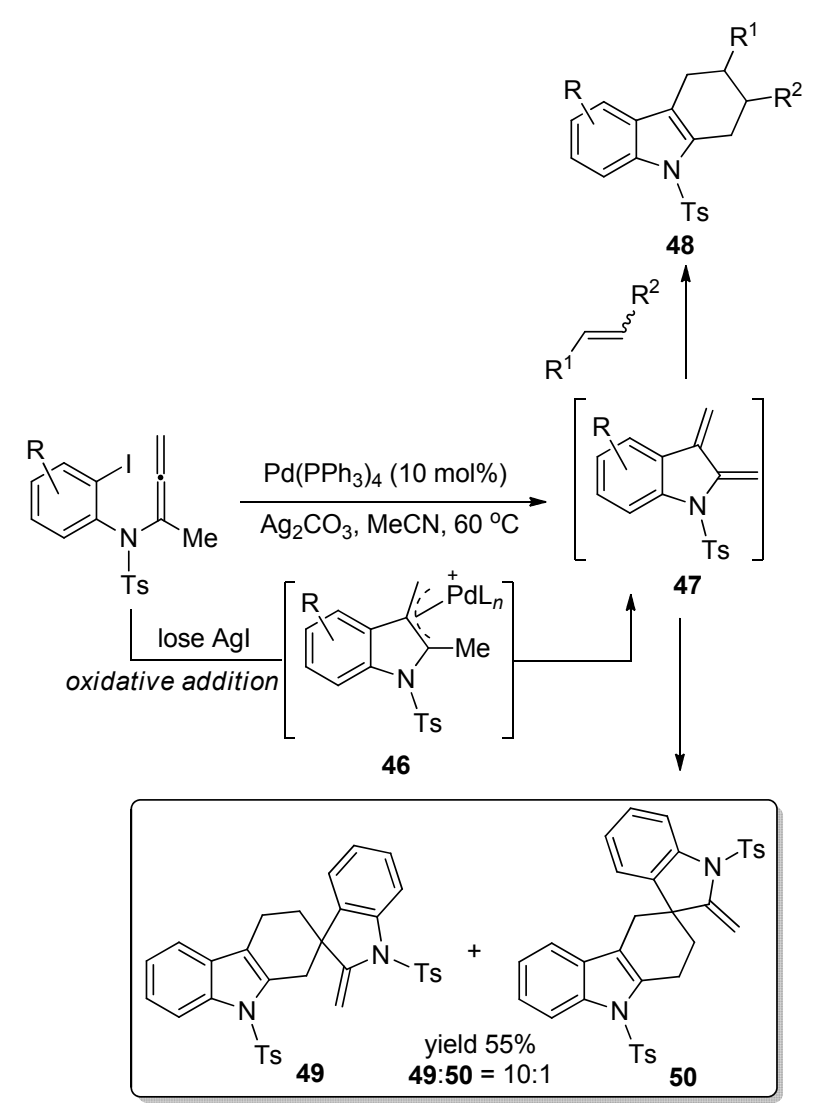

图式 12 钯催化联烯胺分子间 Diels-Alder 环加成反应构建吲 哚衍生物

Scheme 12 Synthesis of indole derivatives by Diels-Alder cycloaddition of Pd-catalyzed allenamides
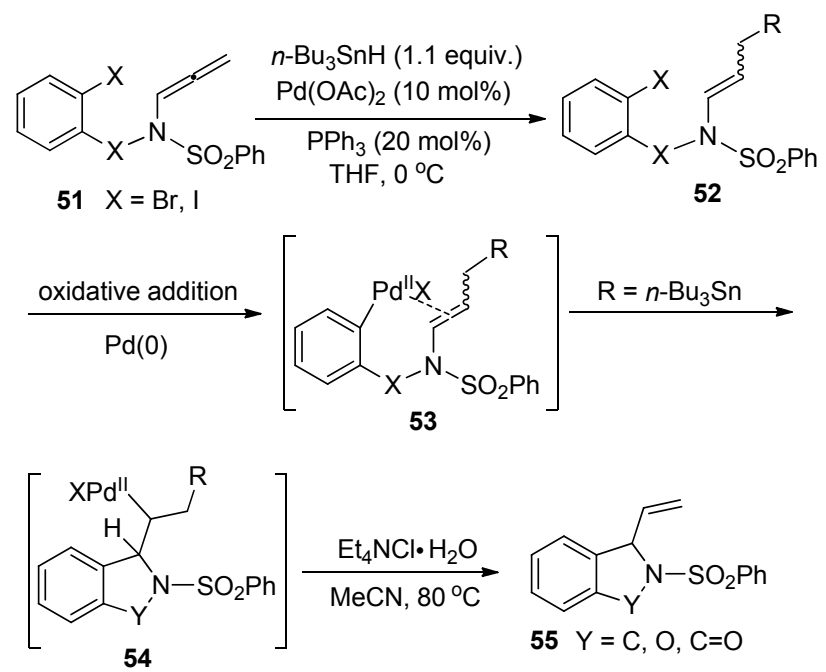

图式 13 锡烷基化-碳钯化串联反应构建含氮、氧杂环的反应 Scheme 13 Tin alkylation-carbon palladium tandem reaction for the reaction of nitrogen and oxygen heterocycles

交换过程，选择性环化得到环化产物 67 和 68. 虽然获 得少量的进攻 $\alpha$ 位环化产物, 但是 Suzuki-Miyaura 型交 叉偶联总体上是具有高度区域选择性的，在碱性条件 

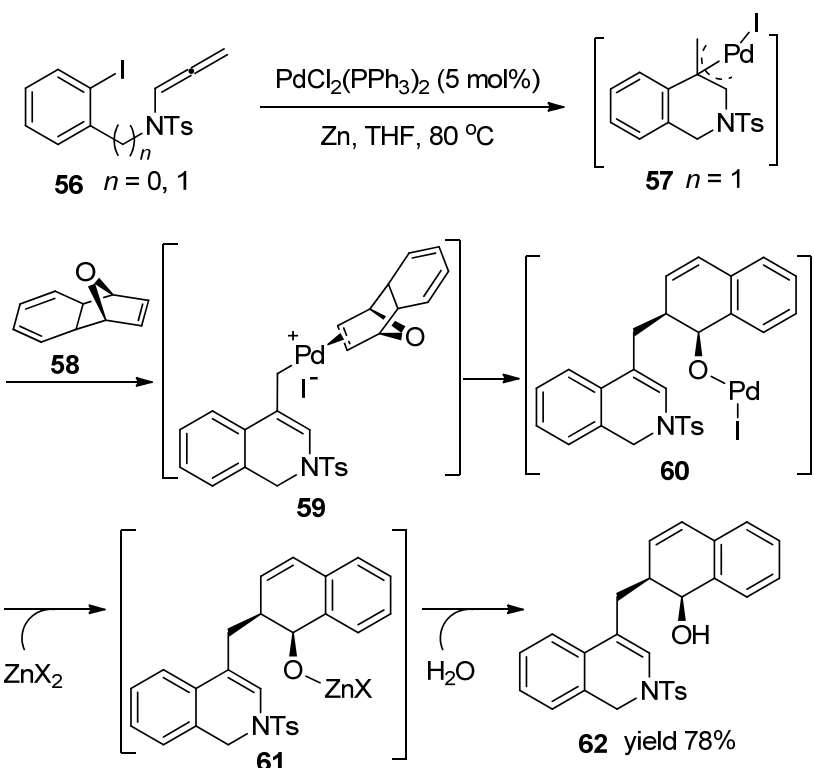

图式 14 新型钯催化联烯胺环化反应

Scheme 14 Novel Pd-catalyzed allenamides cyclization reaction

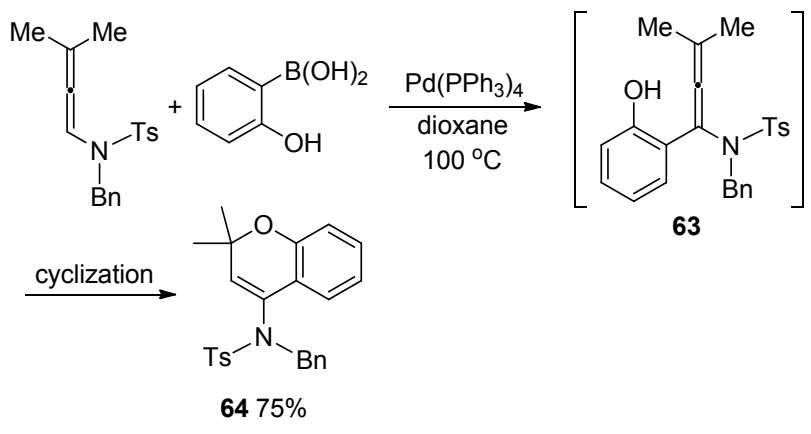

图式 15 钯催化通过 Suzuki-Miyaura 偶联的水解/环化反应

Scheme 15 Pd-catalyzed carbopalladation/cyclization via Suzuki-Miyaura coupling
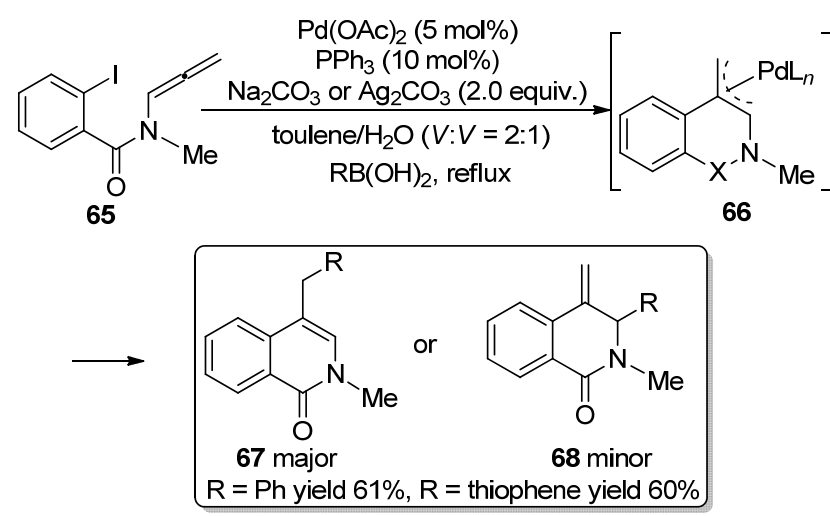

图式 16 钯催化 Suzuki-Miyaura 偶联环化反应

Scheme 16 Pd-catalyzed cyclization of Suzuki-Miyaura coupling

下，反应主要还是发生在空间位阻较小的 $\gamma$ 位碳. 2007 年, Sasaki 课题组 ${ }^{[17]}$ 报道了一种合成 2,3 位取
代吲哚的合成方法(Scheme 17). 利用 $\pi$-烯丙基钯中间体 69 与一系列芳基硼酸进行 Suzuki-Miyaura 偶联，可以高 效地合成二取代吲哚及其衍生物.

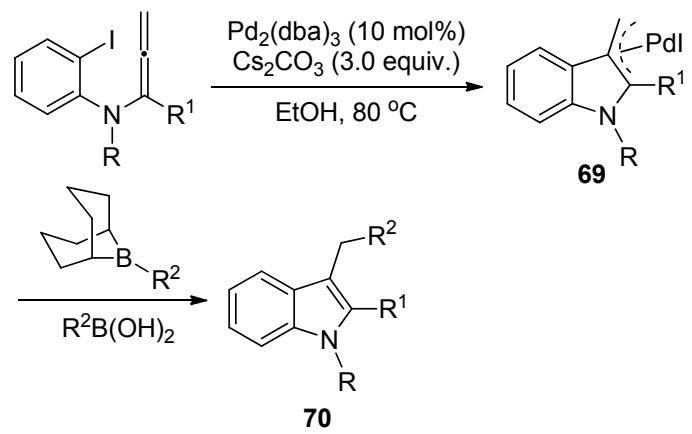

图式 17 钯催化联烯胺环化构建 2,3 取代吲哚反应 Scheme 17 Pd-catalyzed allenamides cyclization to build 2,3 substituted indole reactions

2017 年, 刘会研究组 ${ }^{[18]}$ 报道了一篇 Pd 催化联烯胺 Metallo-Ene/Suzuki 串联环化反应(Scheme 18). 该反应 在 $\mathrm{PdCl}_{2}\left(\mathrm{PPh}_{3}\right)_{2}$ 为催化剂, $\mathrm{K}_{3} \mathrm{PO}_{4}$ 为碱, 二氧六环为溶剂, $50{ }^{\circ} \mathrm{C}$ 的条件下进行, 一锅法实现 $\mathrm{C}\left(\mathrm{sp}^{3}\right)-\mathrm{C}\left(\mathrm{sp}^{2}\right)$ 键的高 效构建.

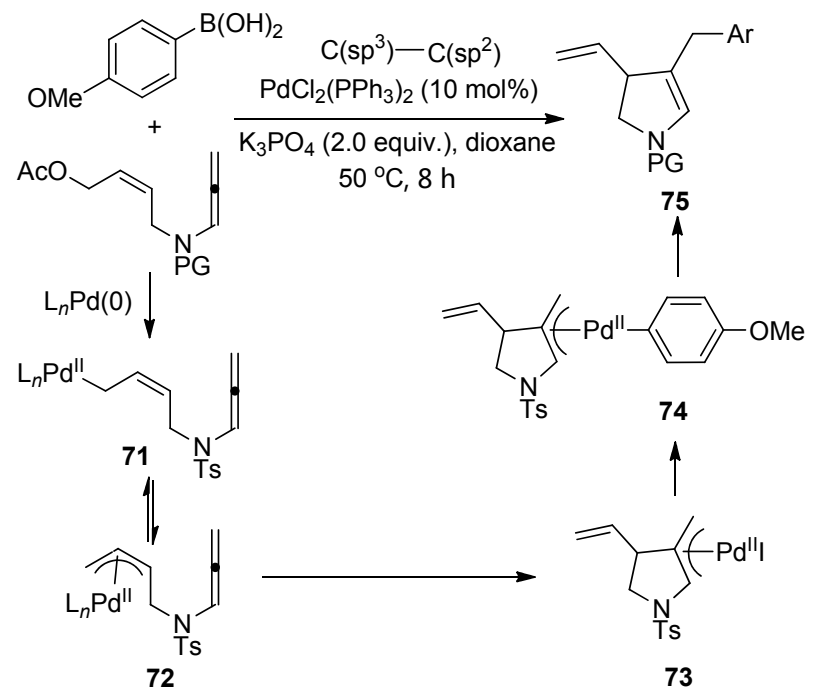

图式 18 钯催化联烯胺 Metallo-Ene/Suzuki 串联反应机理 Scheme 18 Cascade reaction mechanism of Pd-catalyzed allenamides Metallo-Ene/Suzuki

结合 Bäckvall 等课题组相关工作，作者提出了可能 的反应机理(Scheme 18). 首先, $\operatorname{Pd}(0)$ 完成对醋酸乙烯酯 的氧化加成得到中间体 71, 同时可能形成 $\pi$-烯丙基钯 中间体 72, 并且两个中间体之间可能存在相互转化. 接 下来, $\mathrm{Pd}$ 对联烯插入, 分子内环化形成第一个 $\mathrm{C}\left(\mathrm{sp}^{3}\right)$ $\mathrm{C}\left(\mathrm{sp}^{3}\right)$ 键，与此同时，Metallo-Ene 反应产生另一个 $\pi$-烯 丙基钯中间体 73. 随后，中间体 73 与甲氧基苯嗍酸发 生转金属交换，得到中间体 74. 最后经还原消除构建第 二个 $\mathrm{C}\left(\mathrm{sp}^{3}\right)-\mathrm{C}\left(\mathrm{sp}^{3}\right)$ 键, 并得到最终环化产物 75. 在该 
循环过程中, 并没有发生 $\gamma$ 位的还原消除过程, 而是高 选择性地完成 $\alpha$ 位还原消除反应, 得到最终产物.

\section{$1.5 \mathrm{Pd}$ 催化联烯胺 Sonogashira-type 偶联环化反应}

2012 年, Huang 课题组 ${ }^{[19]}$ 报道了一例一锅法合成取 代的异吲哚啉衍生物的反应(Scheme 19). 在该转化中, 首先是双炔丙基酰胺与 $\beta$-碘烯酮 Sonogashira 发生偶联 反应, 生成化合物 78, 并在 1,5-二氮杂二环[4.3.0]壬 烯-5 (DBN) 的诱导下产生异构化反应, 得到联烯胺 79. 随后经历分子内的 $[4+2]$ 环加成反应, 完成芳构化过程, 以较好的产率获得异吲哚啉衍生物 $\mathbf{8 0}$.
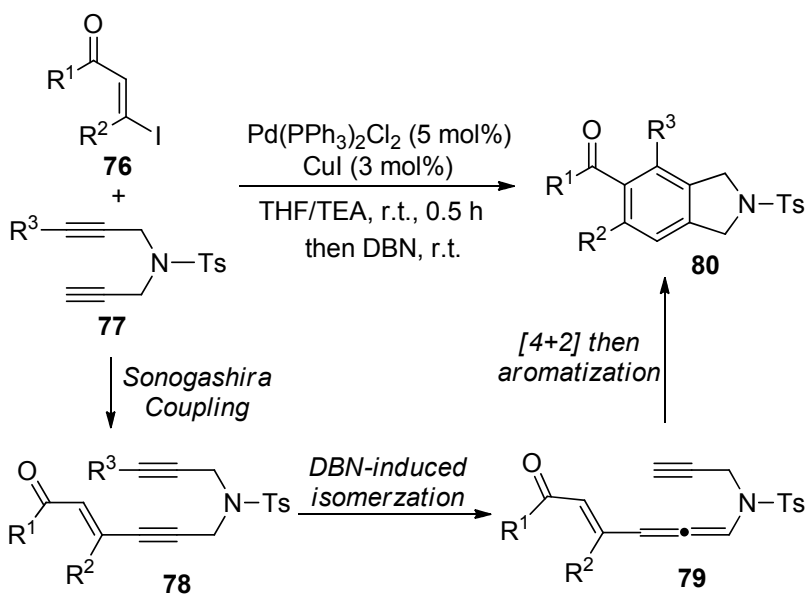

图式 19 一锅法合成取代的异吲哚啉衍生物的反应 Scheme 19 One-pot synthesis of substituted isoindoline derivatives

\section{$1.6 P d$ 催化联烯胺氧化环化反应}

在联烯和联烯胺的研究领域中, Bäckvall 课题组 ${ }^{[20]}$ 做了大量的工作. 他们主要研究联烯化合物在 $\operatorname{Pd}(\mathrm{II})$ 的 催化下形成中间体 $\mathbf{8 1}$ 之后, 进行 Suzuki 偶联、环化、 亲核取代等过程(Scheme 20). 如 Path d 所示, 该团队 ${ }^{[21]}$ 报道了一种新颖的钯催化联烯胺氧化环化反应, 通过该 转化可以得到一系列共扼二烯化合物.

作者研究发现, 烷烃、芳烃以及环状烯烃取代的联 烯胺都能够较好地适配于该转化. 在适当的反应时间 下, 联烯胺能够达到 $100 \%$ 的转化率, 高产率得到产物 83, 同时存在极少量的 Diels-Alder 加成环化产物 (Scheme 21). 但是当苯醌的量增加到 2.1 equiv. 时, 主要 发生的反应是联烯胺和苯醌之间的 Diels-Alder 环加成. Bäckvall 小组进一步研究了该转化, 开发并使用了一种 新型醌衍生物混合催化剂, 如 Scheme 21 所示, 以氧气 为末端催化剂, 在路径 $\mathrm{A}$ 的条件下, 联烯胺的分子内环 化产率达到 $94 \%$, 并且没有形成任何可检测的 Diels-Alder 加合物. 在相同的反应条件下, 联烯胺和 1.0 equiv. 的马来酰亚胺发生氧化-Diels-Alder 反应, 得到环

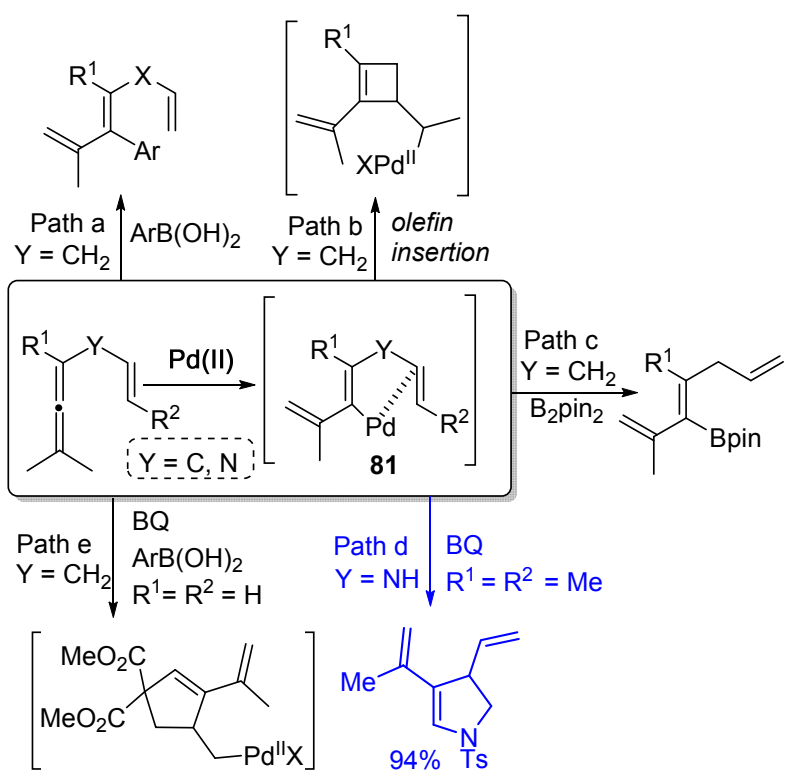

图式 20 Bäckvall 课题组在联烯方面的工作 Scheme 20 Recent work of Bäckvall's group on allenes

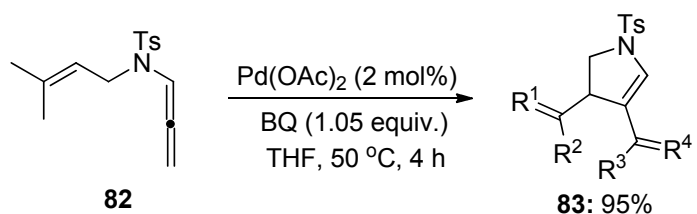

82

83: $95 \%$

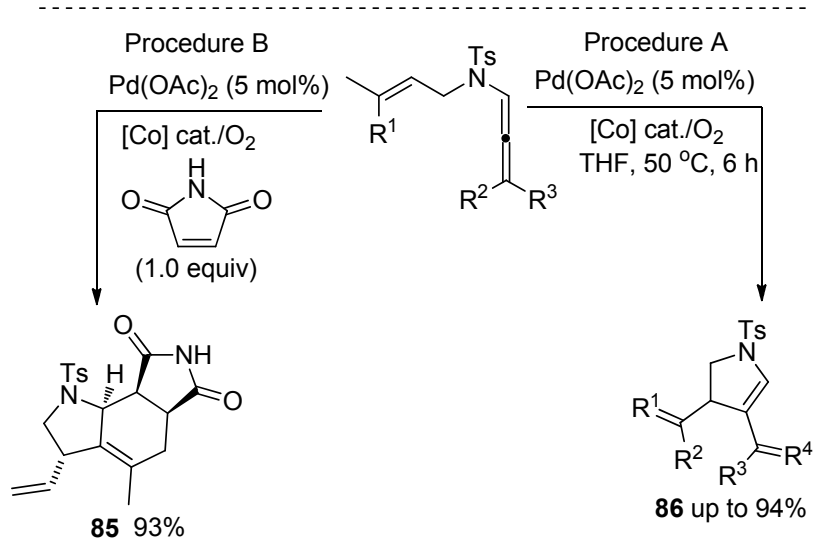

图式 21 Bäckvall 课题组新型氧化联烯胺环化

Scheme 21 Novel oxidation of allene condensates by Bäckvall's group

加成产物 85 的产率达到 $93 \%$. 反应生成的杂环产物是 合成复杂分子的重要中间体. 该氧化策略能够和 DielsAlder 环加成反应相结合，一锅法实现分子间串联环化 反应，成为具有潜在应用价值的合成方法学.

\section{$2 \mathrm{Ru}$ 催化联烯胺环化反应}

以钉卡宾催化剂催化 $\alpha$-烯烃复分解反应已经成为 构建碳碳双键的常用的策略之一，被广泛用于制备复杂 的有机化合物，钓亚烷基催化剂如 $\mathbf{A} \sim \mathbf{D}$ (Scheme 22). 随着对钉催化剂的研究不断深入, 在烯烃异构化 ${ }^{[22]}$ 、氢 
化 ${ }^{[23]}$ 、自由基反应 ${ }^{[24]}$ 、硅烷活化 ${ }^{[25]}$ 、环丙烷化 ${ }^{[26]}$ 、环 丙烷差向异构化 ${ }^{[27]}$ 、氧化 ${ }^{[28]}$ 、氢化乙烯化 ${ }^{[29]} 、[4+2]^{1}$ 环 加成 ${ }^{[30]} 、[3+2]$ 环加成 $^{[31]} 、[2+2+2]^{\text {环加成 }}{ }^{[32]}$ 反应中有 着广泛的应用.
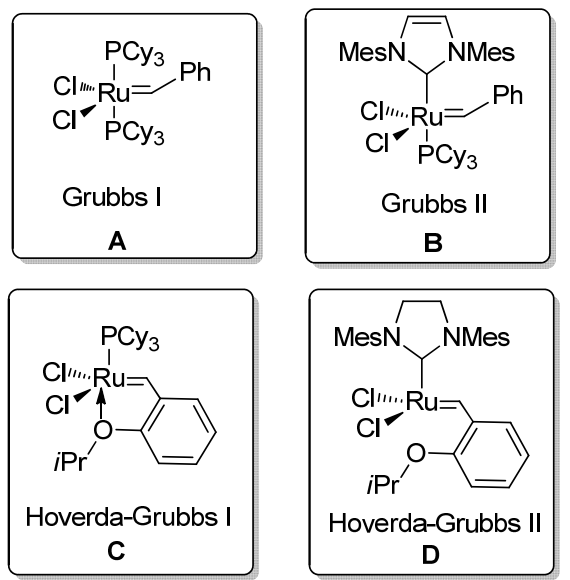

图式 22 Grubbs 催化剂

Scheme 22 Grubbs catalysts

关于钓催化烯烃或者烯胺的关环反应的报道较多, 但是, 钓催化联烯胺加成环化却鲜有报道. 在 2011 年, Hiemstra 课题组 ${ }^{[33]}$ 对联烯胺闭环复分解(RCM)反应进行 了探索(Scheme 23). 以联烯胺 87 作为反应底物, 在钉 催化剂 Grubbs I 和 Grubbs II 的作用下, 最终没有得到关 环的产物, 只得到了联烯胺异构化的产物 88. 作者认为 这可能是由于钓催化剂对分子的丙二烯结构具有更大 的亲和力, 一旦最初的复分解发生在这一端, 将不会与 双键进一步反应。

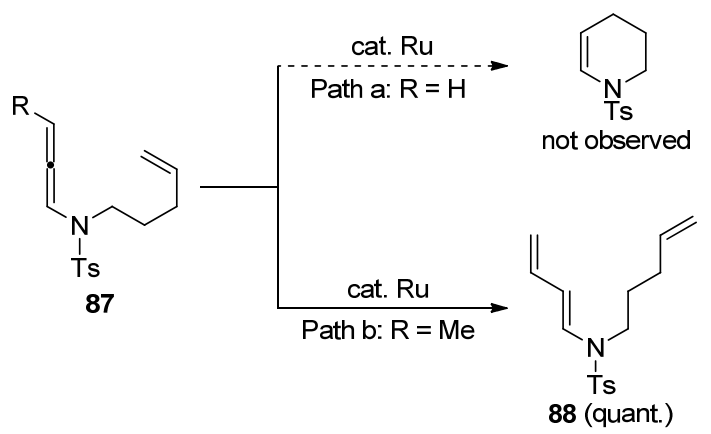

图式 23 Hiemstra 对联烯胺的 RCM 反应探索

Scheme 23 Hiemstra's exploration for RCM reaction of allenamides

2016 年, Arisawa 课题组 ${ }^{[34]}$ 实现了钉催化联烯胺分 子内的 [2+2]环加成反应(Scheme 24), 构筑双环 [3.1.1] 杂环庚烷化合物 89. 这是第一例钓卡宾催化剂催化的 $[2+2]$ 环加成反应报道, 转化在室温下进行, 没有发生 自由基和经典的烯烃复分解反应. 该方法的实现, 将有 助于钓卡宾催化剂更加广泛地应用于功能性分子合成 领域.

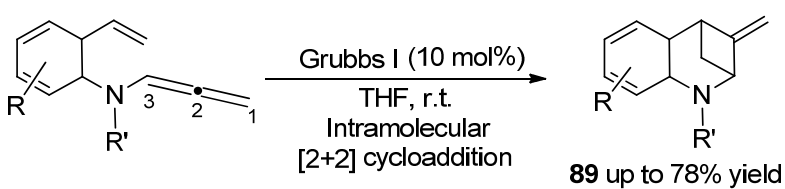

图式 24 Arisaw 钉催化联烯胺分子内的[2+2]环加成反应与 机理

Scheme 24 [2+2] cycloaddition in Arisaw's Ru catalyzed allenamides

\section{Rh 催化联烯胺环化反应}

2006 年, Barluenga 课题组 ${ }^{[35]}$ 首次实现了铑催化联 烯胺与铬烯基-(甲氧基)卡宾复合物的 $[3+2]$ 环加成反 应(Scheme 25), 此过程具有化学和区域选择性, 生成一 系列的酰胺基环戊烯及其衍生物 90. 作者提出了可能 的反应机理: 首先, 铑催化剂与烯基铬卡宾发生转金属 交换，生成活化的烯基 $\mathrm{Rh}(\mathrm{I})$ 卡宾配合物和 $\mathrm{Cr}(\mathrm{CO})_{6}$. 然 后与联烯胺加成环化，经还原消除过程得到环戊烯衍生 物, 并再生催化剂. 在这里, 作者推测 $\mathrm{CO}$ 在该反应中 有两种作用: (1)通过改变反应途径, 提高催化反应效率; (2)可以当量回收 $\mathrm{Cr}(\mathrm{CO})_{6}$. 作者发现，当联烯带有富电 子基团时，在铑卡宾的作用下，联烯胺 $\alpha$ 碳选择性环化 得到[3+2]环加成产物，若联烯带有的取代基为拉电子 基时, 则是联烯胺 $\gamma$ 位碳参与反应.<smiles>[R]C=CC(=CC(=O)OC)OC</smiles>

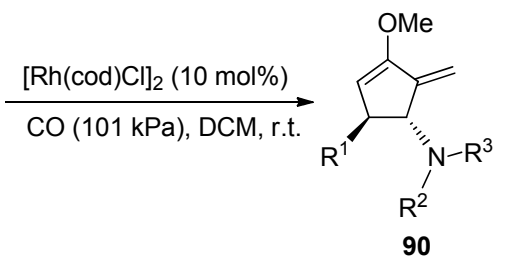

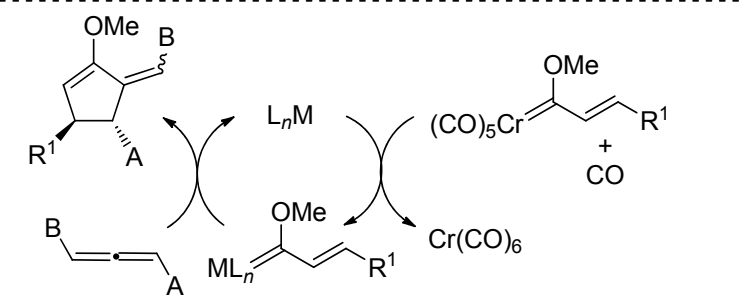

$\mathrm{L}_{n} \mathrm{M}=[\mathrm{Rh}(\operatorname{cod}) \mathrm{Cl}]_{2}$ or $\left[\mathrm{Rh}(\mathrm{CO})_{2} \mathrm{Cl}\right]$ for electron-rich allenes $\mathrm{L}_{n} \mathrm{M}=[\mathrm{Rh}(\operatorname{cod})(\mathrm{CO})]^{+}$for electron-poor allenes

图式 25 铑卡宾催化剂催化联烯胺环加成反应

Scheme 25 Rhodium carbene catalyst catalyzed cycloaddition reaction of allenamides

作者探究机理时认为, 无论 $\mathrm{CO}$ 的存在与否, 铑卡 宾的获得是氧化铬配合物与 $\left[\mathrm{Rh}(\operatorname{cod})(\text { naphthalene) }]^{+}\right.$相 互作用的结果. 同时，在反应过程中，卡宾配合物自身 不会发生配体 COD-CO 的相互交换. 该环加成过程具 有的区域选择性和非对映选择性，以及所得环加成物具 有易水解的特性，使得该方法成为制备官能化的 3,4-二 
取代的 2-亚烷基环戊酮的简单而有效的方式.

2008 年, Brummond 课题组 ${ }^{[36]}$ 首次报道了 $\mathrm{Rh}(\mathrm{I})$ 催化 炔基联烯胺分子内的环化反应 (Scheme 26). 与 Barluenga 等的工作不同点在于: 无论取代基的电性如 何, 最终只能得到 $\alpha$ 碳的环加成产物, 且化合物分子内 同时含有三个不饱和烯烃, 可以进行更多转化, 因此具 有更大的潜在应用价值. 在该转化中, 将气氛从氩气转 变为一氧化碳时, 反应以 Pauson-Khand 方式生成具有 非对映选择性的复杂三并环结构化合物 91.

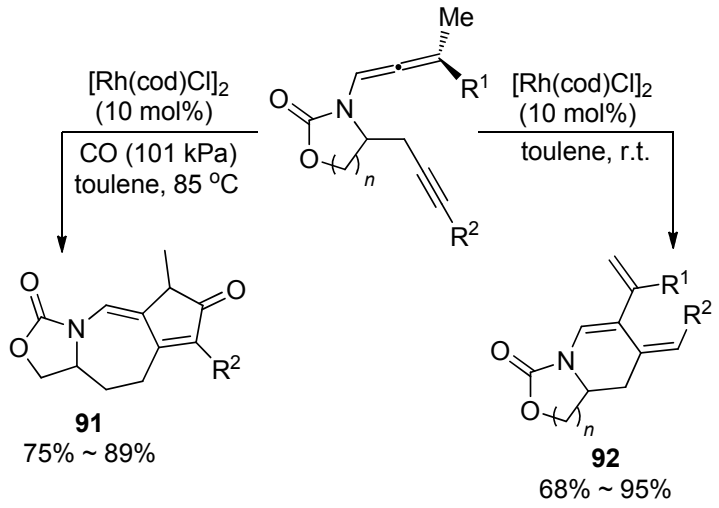

图式 26 铑催化炔基联烯胺分子内的环化反应 Scheme $26 \mathrm{Rh}(\mathrm{I})$ catalyzed cyclization of alkynyl allenamides

2013 年, Charette 课题组 ${ }^{[37]}$ 报道了一例 Rh(II)催化 的联烯胺和 $\alpha$-氰基重氮酯分子间环丙烷化反应(Scheme 27). 该反应的区域选择性发生在联烯胺空间位阻更小 的端位碳上, 与 Barluenga 工作类似, 铑催化剂与 $\alpha$-氰 基重氮酯生成氰基取代的 $\mathrm{Rh}(\mathrm{II})$ 金属卡宾, 相继的环加 成和还原消除后得到环丙烷环产物 93 , 具有较高的 $E / Z$ 比和 $e e$ 值.<smiles>C=C=CN1C(=O)c2ccccc2C1=O</smiles>

\section{Method A:}

$\mathrm{Rh}_{2}(\mathrm{OPiv})_{4}(1 \mathrm{~mol} \%)$ $\mathrm{DCM}, 0^{\circ} \mathrm{C} \sim$ r.t. Method B: $\mathrm{Rh}_{2}(\mathrm{~S}-\mathrm{IBAZ})_{4}(1 \mathrm{~mol} \%)$ $\mathrm{PhH} /$ Mesitylene, $0^{\circ} \mathrm{C} \sim$ r.t.

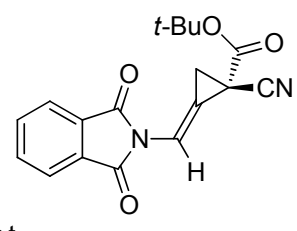

93

$95 \%, E / Z>97: 3$

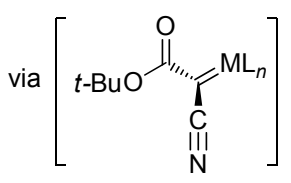

more electrophilic carbene

图式 27 铑催化的联烯胺和 $\alpha$-氰基重氮酯分子间环丙烷化反 应

Scheme $27 \mathrm{Rh}(\mathrm{II})$ catalyzed cyclopropanation of allenamides and $\alpha$-cyanodiazonium esters

在过去的几十年中, 虽然联烯分子的 $[2+2]$ 环加成
反应的报道较多，但头对头、尾对尾、头对尾的区域选 择性的控制仍然是一个较大的挑战. 最近, 康强课题组 和张俊良课题组分别报道了 $\mathrm{Rh}$ 催化的联烯胺 $[2+2]$ 和 $[3+2]$ 环加成反应.

2016 年, 康强课题组 ${ }^{[38]}$ 报道的联烯胺分子自身环 加成方式为头对头, 反应生成具有高度区域和立体选择 性的反式-二亚甲基环丁烷-二胺及其衍生物 (Scheme 28). 该反应在高沸点的邻二氯苯为溶剂的条件下实现 的，首先是 $\mathrm{Rh}(\mathrm{I})$ 催化剂与磺酰基氧进行配位，同时与联 烯胺反应得到中间体 95, 另一分子的联烯胺异构化得 到亚胺中间体 96. 随后, 亚胺中间体作为亲核试剂进攻 中间体 95 上的联烯中心碳原子，得到偶联中间体 97 . 最后, 消除 $\mathrm{Rh}$ 配合物关环产生 $[2+2]$ 环加成产物 94. 值 得注意的是，当联烯胺的 $\alpha$ 位碳原子上带有取代基时， 反应则不能够顺利进行, 作者认为 $\alpha$ 位碳原子上的取代 基阻止了稳定亚胺中间体的生成，终止了反应循环.
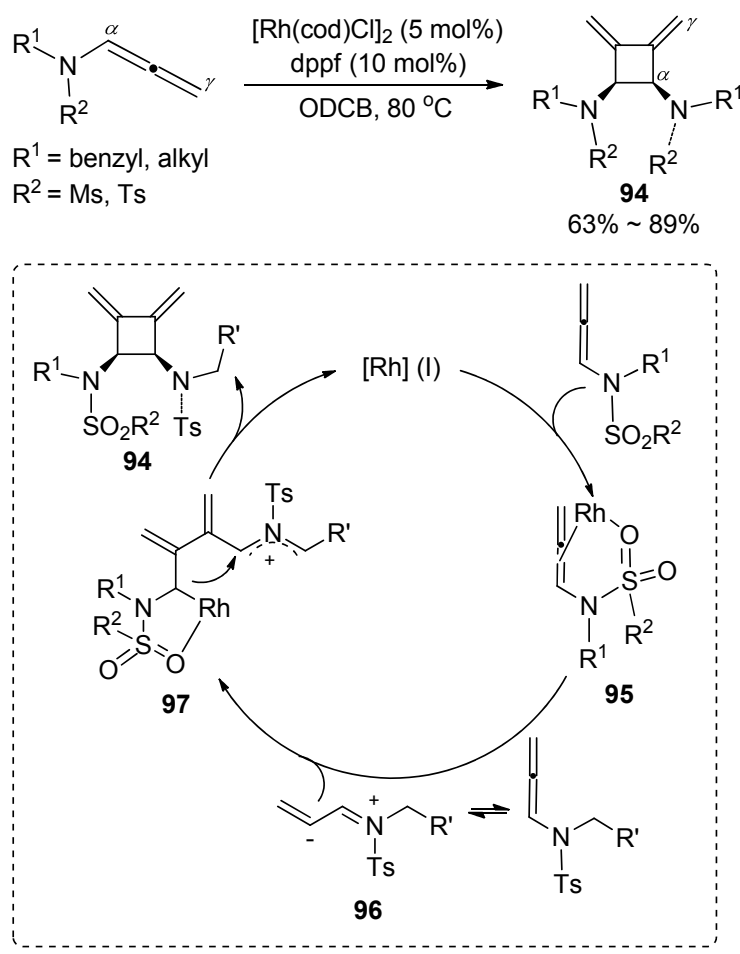

图式 28 非铑卡宾催化的联烯胺环加成反应

Scheme 28 Non-Rh-carbene-catalyzed cycloaddition of allenamides

相比于 $\mathrm{Rh}$ 卡宾催化, 张俊良课题组 ${ }^{[39]}$ 报道的是铑 催化联烯胺与烯基氮杂环丙烷化合物间的 [3+2]环加成 反应(Scheme 29). 首先是 $\mathrm{Rh}(\mathrm{I})$ 催化剂对环丙烷化合物 氧化加成, 开环得到 $\mathrm{Rh}(\mathrm{III})$ 中间体, 然后选择性地对联 烯胺 $\mathrm{N}$ 邻位 $\mathrm{C}=\mathrm{C}$ 双键插入，分子内环化，最后经还原 消除得到环加成产物 99, 并再生 $\mathrm{Rh}(\mathrm{I})$ 催化剂参与反应 循环，制备了一系列的手性四氢吡咯类化合物. 

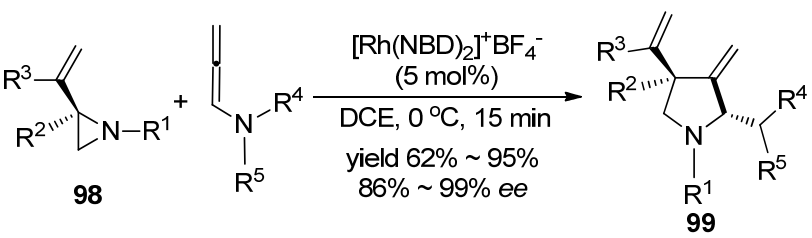

图式 29 Zhang 课题组铑催化的联烯胺环加成反应

Scheme 29 Rh-catalyzed ring cycloaddition reaction of allenamides from Zhang group

\section{$4 \mathrm{Au}$ 催化联烯胺环化反应}

近几十年来, 金催化联烯胺的反应的报道较多, 催 化联烯胺的反应类型主要有环化反应、环加成反应、不 对称催化以及亲核取代等. 金催化联烯胺是钯催化之后 又一重要的反应类型, 由于金催化的研究报道众多, 在 本节中, 我们从环化、 $[2+2] 、[3+2] 、[4+2] 、[2+$ $2+2]$ 环加成分别进行介绍.

2006 年, Hegedus ${ }^{[40]}$ 实现了 $\mathrm{Au}$ 催化手性 $\gamma$-取代的联 烯胺化合物环化过程(Scheme 30), 合成一系列高度官 能化的顺式二氢呋喃. 首先, 金完成对联烯胺的插入, 分子内的氧亲核试剂容易进攻氮原子邻位的碳, 发生分 子内亲核取代反应，环化得到最终的含氧五元产物 101.<smiles>[R]C(O)C(C)=CC=CN1C(=O)C[C@H](c2ccccc2)[C@@H]1c1ccccc1</smiles>

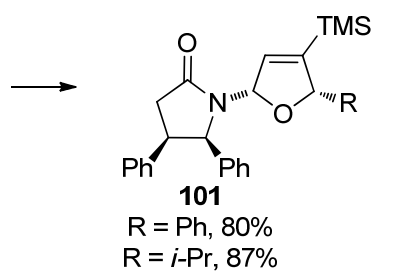

图式 30 金催化手性 $\gamma$-取代的联烯胺化合物环化过程 Scheme 30 Au catalyzed cyclization of chiral $\gamma$-substituted allenamide compounds

2007 年, Fujii 和 Ohno 研究团队 ${ }^{[41]}$ 首次实现了 $\mathrm{Au}(\mathrm{I})$ 催化联烯胺分子内环化制备二氢喹啉类化合的方法 (Scheme 31). 作者认为, $\mathrm{Au}(\mathrm{I})$ 催化剂在配体的作用下, 完成对联烯胺的活化，分子内环化得到烯基金中间体， 由于正离子的不稳定性, 发生质子化转移, 最终进行芳 烃异构化，完成苯并哌啶环的构建.

2009 年, Pérez-Castells 等 ${ }^{[42]}$ 报道了 $\mathrm{Au}$ 催化的联烯 胺和亲核试剂分子间的环化反应(Scheme 32). 作者认 为金作为催化剂启动反应, 优先完成对丙二烯结构的插 入, 而不是像在烯炔环化中的首先对参键的插入, 在亲 核试剂的作用下发生偶联. 随后, $\mathrm{Au}$ 催化剂完成对参键

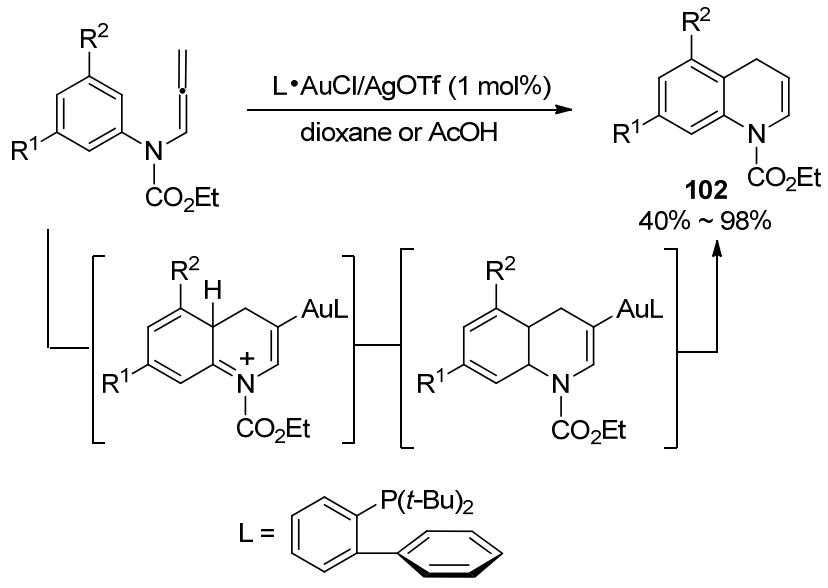

图式 31 联烯胺分子内环化制备二氢喹啉类化合的方法 Scheme 31 Method for preparing dihydroquinoline compound by intramolecular cyclization of allenamides

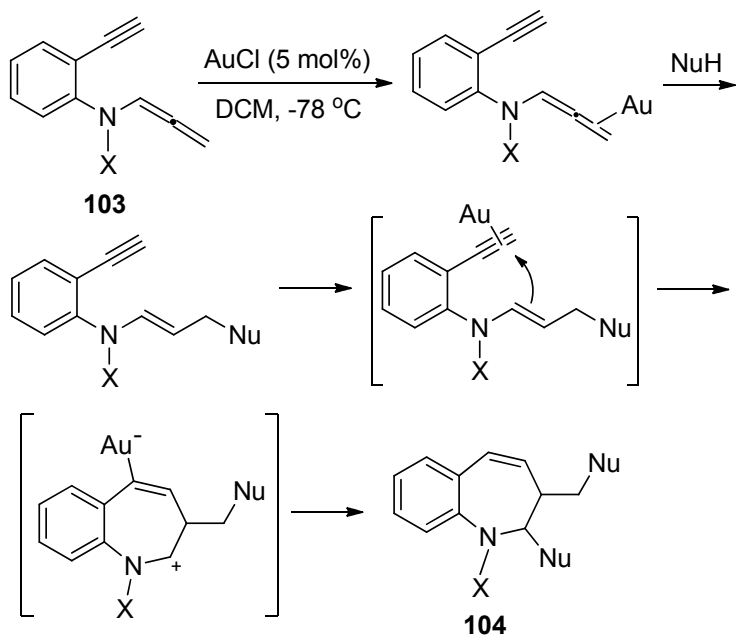

图式 32 金催化的联烯胺和亲核试剂分子间的环化反应 Scheme 32 Au-catalyzed cyclization between allenamides and nucleophile molecules

插入活化, 环化得到最终产物 104, 值得注意的是, 如 果氮原子上取代基的拉电子效应弱于磺酰基，该环化过 程则不能顺利的进行.

2012 年, Hsung 课题组 ${ }^{[43]}$ 报道了一例 $\alpha$ 取代的联烯 胺环化反应(Scheme 33). 在作者提出的反应机理中, $\mathrm{Au}$ 催化剂首先完成对丙二烯的插入，得到亚胺中间体，然 后发生 Imino-Nazarov 环化反应，得到区域选择性产物 108. 该转化为构建稠合的环戊烯酰胺提供了一种有效 的合成方法, 并且产率高达 97\%.

$\mathrm{Au}$ 催化联烯胺环加成反应，同样还是有效构建四 元、五元、以及七元、八元大环有用的方法之一. 2011 年，陈自立课题组 ${ }^{[44]}$ 报道了第一例金催化联烯胺[2+2] 环加成反应(Scheme 34). 该反应是在金催化联烯胺和 富电子烯烃完成环加成后实现的，如果联烯胺的 $\alpha$ 或者 $\gamma$ 位上存在取代基, 则不能够分离到环化产物. 作者认 


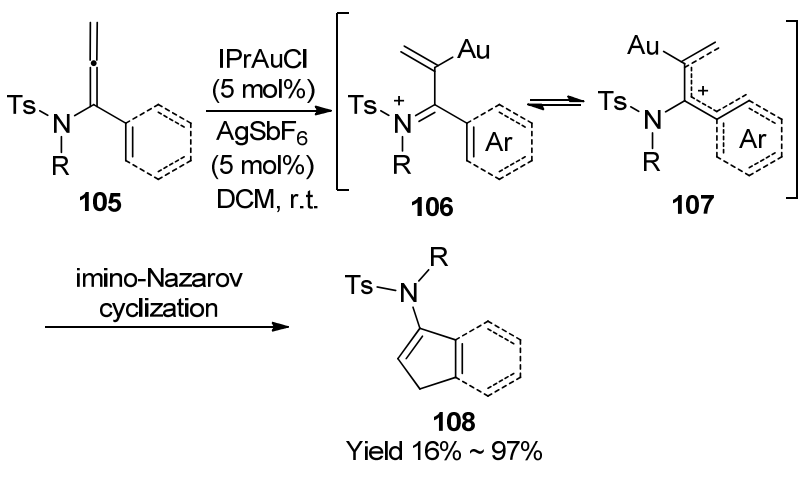

图式 33 金催化 $\alpha$ 位芳基取代联烯胺的 Imino-Nazarov 环化反 应

Scheme 33 Au-catalyzed Imino-Nazarov cyclization of a-aryl substituted allenamide

为, 由于四元环的张力较大, 如果存在取代基, 较大的 空间位阻会阻碍环加成反应的顺利进行. 同时, 在不存 在富电子烯烃的情况下，金能够催化联烯胺自身之间以 头一尾的方式发生聚合反应，得到二烯的环丁烷化合物 109. 为了避免在富电子烯烃的环加成反应中得到二聚 化合物, 作者篮选了合适的配体, 在配体调控下, 以更 高的区域和立体选择性得到目标产物 $\mathbf{1 1 0}$.

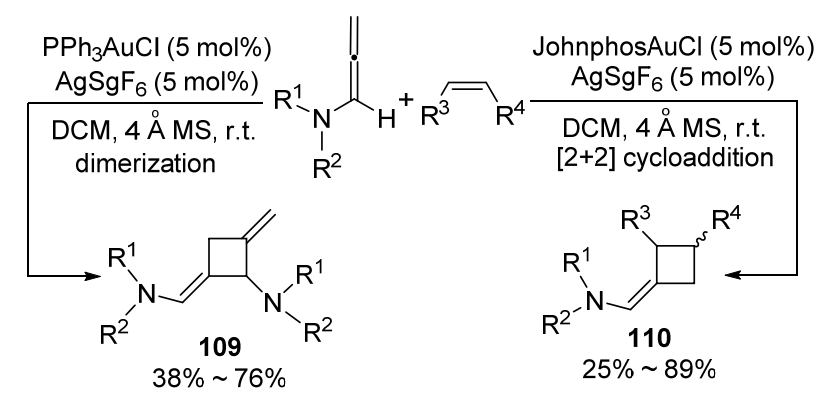

图式 34 金催化联烯胺与烯烃的 $[2+2]$ 环加成反应 Scheme 34 Au-catalyzed allenamides [2+2] cycloaddition with olefins

2012 年, Mascareñas 课题组 ${ }^{[45]}$ 报道了相似的工作, 即联烯胺和烯烃在金的催化下, 高区域选择性地完成 $[2+2]$ 环加成反应(Scheme 35). 与陈自立课题组工作不 同的是, 在 Mascareñas 教授实现的转化中, 烯烃的选择 范围更加广泛, 并且当作者将此环加成方案应用于不同 构型的烯烃时, 具有非常好的选择性, 可以得到单一的 反式一立体异构体. 作者认为该串联反应的机理如下: 金催化剂完成对丙二烯的插入, 得到阳离子金中间体 111, 接受烯烃的进攻, 再次得到阳离子中间体 112. 当 使用环状或非环状烯酰胺时, 形成更稳定的苄基或 $N$ 酰基亚胺鎓阳离子会增加该反应的区域选择性. 但是, 由于 $\delta$ 碳一碳键的易旋转性, 得到更小的空间位阻, 使得 烯烃立体化学性降低. 最后, 在氮原子的辅助下, 完成

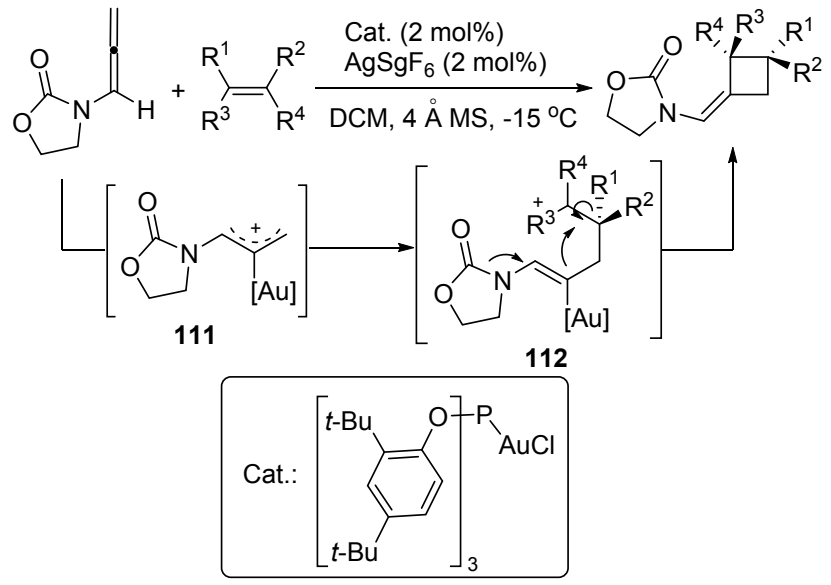

图式 35 金催化联烯胺与烯烃间 $[2+2]$ 环加成反应 Scheme 35 Au-catalyzed $[2+2]$ cycloaddition reaction between allenamides and olefins

闭环, 并经过还原消除过程, 再生 $\mathrm{Au}$ 催化剂.

同年, González 课题组 ${ }^{[46]}$ 完成了联烯胺和烯醇醚的 金催化 $[2+2]$ 环加成反应(Scheme 36). 与 Mascareñas 课 题组报道的催化剂相同, 但是用量却少很多, 经济节能 效果更好. 同时得注意的是, 作者还突破了陈自立课题 组实现环加成反应的局限性, 即在该策略下, $\gamma$ 位取代的 联烯胺同样能够便显出较好的反应性, 得到 4-取代环丁 烷结构.

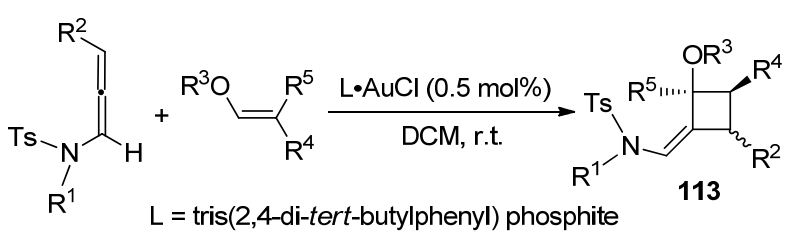

图式 36 金催化联烯胺与烯醇醚 $[2+2]$ 环加成反应

Scheme 36 Au-catalyzed [2+2] cycloaddition of allenamides with enol ethers

2015 年, Bandini 课题组 ${ }^{[47]}$ 实现了金催化联烯胺和 吲哚及其衍生物之间的环加成反应(Scheme 37). 该转 化中所使用的 $\left.\left[\mathrm{JohnPhosAu}^{-} \mathrm{NCMe}\right)\right] \mathrm{SbF}_{6}$ 催化剂为商业 化产品, 容易获取, 并且底物的适应性更好, 条件更温 和. 同时, 该 $[2+2]$ 环加成反应的区域和非对映选择性 更强. 但是, 作者研究发现, 吲哚取代基只能是拉电子 基如 Boc 等, 才能够表现出较好的适应性, 给电子保护 基则没有反应性. 该方法的实现有助于(一)-tubifoline等 天然产物的全合成.

随着对金催化联烯胺研究的不断深入, 环加成反应 也被陆续报道. 2013 年, 陈自立课题组 ${ }^{[48]}$ 探索出了联烯 胺和硝酮之间[3+2]环加成反应制备手性异噁唑烷 115 的实用新型方案 (Scheme 38). 该反应是在改性的 BINOL 衍生的手性氨基磷酸酯 $\mathrm{Au}(\mathrm{I})$ 催化剂催化下实现 


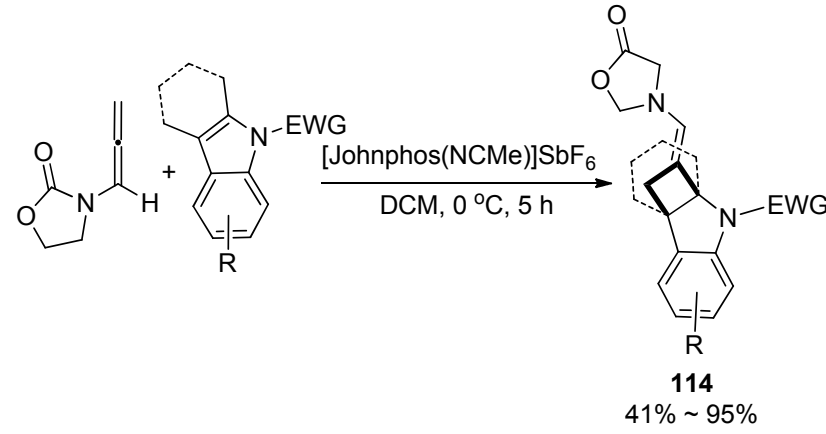

图式 37 金催化联烯胺和吲哚及其衍生物之间的 $[2+2]$ 环加 成反应

Scheme 37 Au-catalyzed [2+2] cycloaddition between allenamides and hydrazines derivatives

的，表现出良好的区域选择性. 其中加入过量 $(5 \mathrm{~mol} \%)$ 的银盐以减少额外的金-硝酮配位数, 并提高金阳离子 的催化活性. 在联烯胺取代基为 $\mathrm{Ts}$ 等酰基情况下，配体 L 表现出较好的适应性, 但是, 当氮原子上的取代基为 呋喃酮等环状结构时，配体 $\mathbf{L}$ '能展现出更良好的对应选 择性.

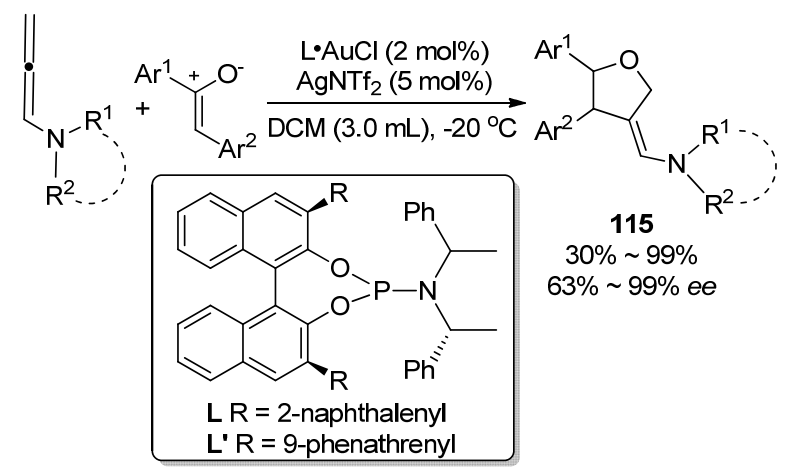

图式 38 金催化联烯胺和硝酮之间 [3+2]环加成反应

Scheme 38 Au-catalyzed [3+2] cycloaddition reaction of allenamides with nitrones

与之前大量报道的联烯胺 $\alpha$ 碳参与环加成的方式不 同, 2015 年, 张俊良课题组 ${ }^{[49]}$ 报道了一例 $\mathrm{Au}(\mathrm{I})$ 催化的联 烯胺邻位碳碳双键和烯炔基酮化合物 116 之间的 [3+2] 环加成反应(Scheme 39). 在配体的调控下, 反应所得产 物均具有较好的区域选择性和对映选择性. 并且在温和 的条件下产率优良, 同时, 该转化原料的易得性, 使得 该方法在合成有机分子骨架时具有较高的实用性和高 效性.

2016年, 刘瑞雄课题组 ${ }^{[50]}$ 报道了金催化联烯胺[3+ 2]环加成反应(Scheme 40), $\alpha$-芳基重氮腈与联烯胺在二 氯甲烷中反应产生 1 -氨基- $1 H$-狮. 在底物的适配性探索 时，作者发现，只有当联烯胺 $\gamma$ 位的取代基都为甲基时， 才能使联烯胺氮邻位的 $\mathrm{C}=\mathrm{C}$ 双键参与反应, 得到产物

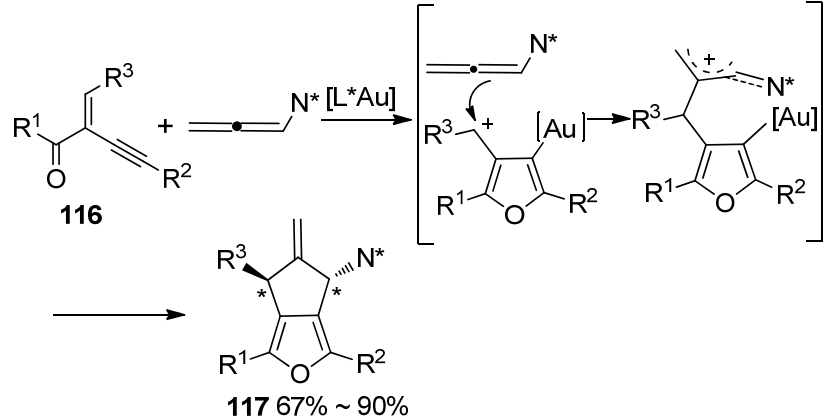

图式 39 金催化的联烯胺和烯炔基酮化合物之间的 $[3+2]$ 环 加成反应

Scheme $39 \mathrm{Au}(\mathrm{I})$ catalyzed $[3+2]$ cycloaddition reaction between allenamides and alkynyl ketone compounds

119 ，这些杂环结构分子的成功获得依赖于 $\alpha$-氧基芳基 卡宾碳烯的高亲电子性. 当 $\mathrm{X}$ 取代基为卤素时, 会对该 转化造成一定影响.

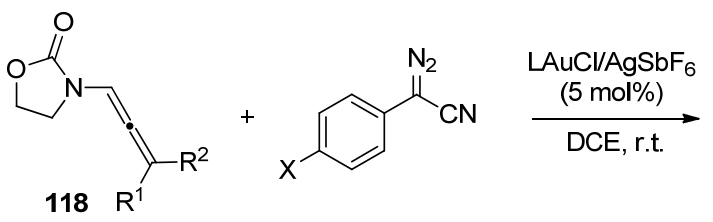<smiles>[R]CC1=C(C#N)c2ccc([X])cc2C1N1CCOC1=O</smiles>

$119 a$

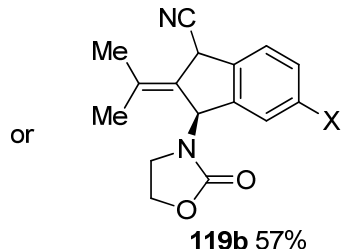

$119 b 57 \%$
图式 40 金催化联烯胺与 $\alpha$-芳基重氮腈间 $[3+2]$ 环加成反应 Scheme 40 Au-catalyzed allenamines with $\alpha$-aryl diazonitriles $[3+2]$ cycloaddition reaction

2011 年, López 和 Mascareñas 等 ${ }^{[51]}$ 报道了首例金催 化联烯胺和非环状共轭二烯烃之间的 $[4+2]$ 环加成反应 (Scheme 41), 转化表现出良好的原子利用率和较高的 $Z$ 选择性. 联烯胺相比于其他的底物如联烯或者联烯基 醚，具有更大的优越性，更高的适配性。该方法成功的 关键是使用新型轴向手性 $N$-杂环卡宾-金催化剂. 该反 应为合成各种环已烯化合物提供了一种通用的方法. 2012 年，该小组对 [4+2]环加成反应做了进一步的探 索 ${ }^{[52]}$, 非对映选择性的实现了第一例联烯胺 $[4+2]$ 环加 成(Scheme 41), 在含有轴向手性三唑并异喹啉-3-亚基 金配体的调控下，实现联烯胺和共轭双烯之间的反应， 获得一系列环己烯化合物 $\mathbf{1 2 1}$.

2013 年, Vicente 课题组 ${ }^{[33]}$ 实现了 JohnPhos-Au 催化 联烯胺和 2-烯基吲哚间的[4+2]加成环化(Scheme 42), 反应得到取代的四氢咔唑类化合物 $\mathbf{1 2 2}$, 丰富了 [4+2] 环加成反应方法学. 


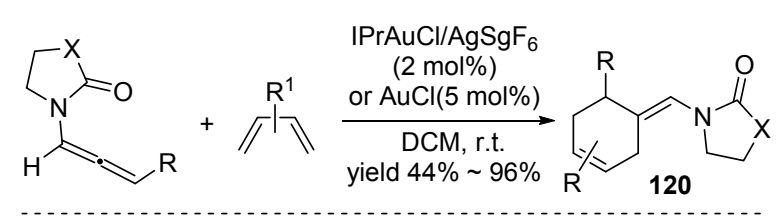

López and Mascareñas (2012)

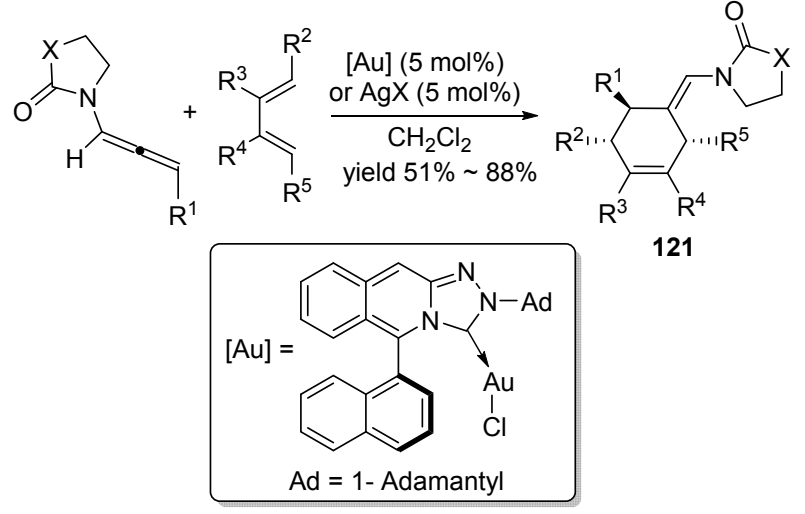

图式 41 金催化联烯胺和非环状共轭二烯烃之间的[4+2]环 加成反应

Scheme 41 Au-catalyzed [4+2] cycloaddition between allenamides and acyclic conjugated

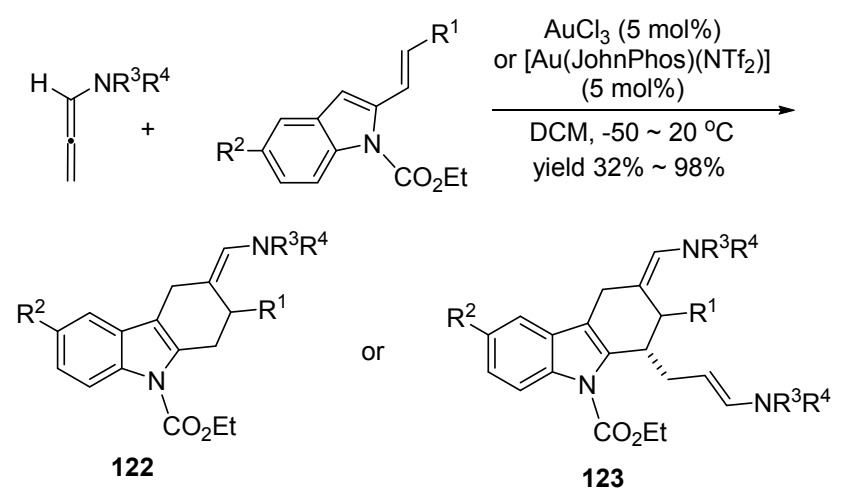

图式 42 金催化联烯胺和 2-烯基吲哚间的[4+2]环加成反应 Scheme 42 Au-catalyzed $[4+2]$ cycloaddition reaction between allenamides and 2-vinyl indoles

López 和 Mascareñas 等 ${ }^{[54]}$ 在 2013 年报道了一例联 烯胺与烯基酮之间的新型的环加成反应(Scheme 43). 作者通过内部亲核试剂截取阳离子中间体 $\mathbf{I}$, 以 endo 型 或者 exo 型串联环化反应得到稠合或桥接双环骨架. 通 过该反应途径, 可以实现合成六元一九元的氧桥分子结 构. 转化经历相似的反应机理: 金首先完成对联烯的活 化，得到碳正离子中间体，随后，该中间体被底物 124 中的羰基氧捕获形成桥联中间体，最后，烯胺进攻活泼 的碳正离子, 环化得到化合物 125 并再生催化剂，该反 应的配体结构如 Scheme 43 所示.

2015 年, 该课题组对联烯胺环加成反应进行持续 的探索 ${ }^{[55]}$, 利用相同的催化剂 129 (Scheme 43), 实现了
联烯胺和烯烃以及不饱和醛之间三组分的 $[2+2+2]$ 加 成环化，得到了多取代的四氢吡喃化合物。该分子骨架 中的酰胺结构为进一步活化制备生物活性产物 Aspergillide A 和 Decytospolide B 提供了更多的潜在可能性. 同 时，这一策略的实现，为多组分环加成反应制备含氮、 氧杂环开辟了新的途径.

2017 年, Mascareñas 和 López 等 ${ }^{[56]}$ 报道了一种简便 直接, 更加具有原子经济性地制备多取代四氢吡喃衍生 物的方法 (Scheme 43). 三组分联烯胺和烯烃以及不饱 和醛在手性 $N$-杂环卡宾-金催化剂 130 或 131 的催化下, 完成具有非对映选择性和对映选择性的 $[2+2+2]$ 环加 成过程, 并为具有光学活性的 2,6-二取代的 cis 和 trans THPs 的合成提供了更加合理有效方法.

2017 年, 孙江涛课题组 ${ }^{[57]}$ 进一步完善了金催化 $[2+$ $2+2$ ]加成环化策略 (Scheme 44). 该反应以 $\mathrm{PPh}_{3} \mathrm{AuCl}$ 为 催化剂, 1,3,5-三嗪与联烯胺在温和条件下转化得到含 氮六元杂环化合物 132 , 产率较高, 同时具有良好的区 域选择性. 当联烯胺 $\gamma$ 位存在取代基时，联烯胺也能表 现出较好的反应性. 该工作与张俊良课题组 ${ }^{[39]} 2016$ 年 发表工作相似之处在于, 不同的官能化的联烯呈现完全 不同的环加成途径. 经过控制实验与机理验证表明, $\mathrm{Au}$ 催化循环经历碳正离子形成、亲核加成、亚胺中间体形 成、环化异构化等过程, 逐步完成 $[2+2+2]$ 加成环化.

\section{Co 催化联烯胺环化反应}

2004 年, Pérex-Castells 课题组 ${ }^{[58]}$ 首次实现了钴催化 联烯胺与炔烃分子间 Pauson-Khand 环化反应(Scheme $45)$, 得到带有 $E$ 酰胺的官能化环戊烯酮类化合物, 具有 良好的产率以及区域选择性.

\section{$6 \mathrm{Ag}$ 催化联烯胺环化反应}

2013 年, Wan 课题组 ${ }^{[59]}$ 以 $N$-炔丙基脂 134 作为底物, 报道了一例 $\mathrm{Ag}$ 催化的联烯胺环化反应(Scheme 46). 作 者将易脱去的羧基引入底物结构, 通过脱羧反应, 分子 内环化得到乙烯基噁唑类五元环化产物. 他们对该转化 提出了可能的反应机理(Scheme 46): 首先, 银催化剂和 炔丙基酯相互作用得到 $\pi$-配合物 137, 同时, 酰氧基还 与 $\mathrm{Ag}(\mathrm{I})$ 配位以促进随后的转化, 经过分子内 6-endo-dig 对酰胺上的羰基氧进行亲核进攻形成中间体 138 , 进一 步形成联烯中间体 139. 随后, 亚胺上的氮接受联烯中 心碳原子的亲核攻击，接着产生两性离子中间体 $\mathbf{1 4 0}$, 通过磺酰基 [3,3]重排的方式得到噁唑化合物 135. 作者 设想在 $\mathrm{Ag}$ 的催化下, 经历和炔丙基酯重排的相似过程, 但结果发现，并没有得到相应的环化产物. 作者认为, 丙二烯结构被 $\operatorname{Ag}(\mathrm{I})$ 阳离子活化, 随后在酰胺部分氧原 
Mascareñas and López (2013)
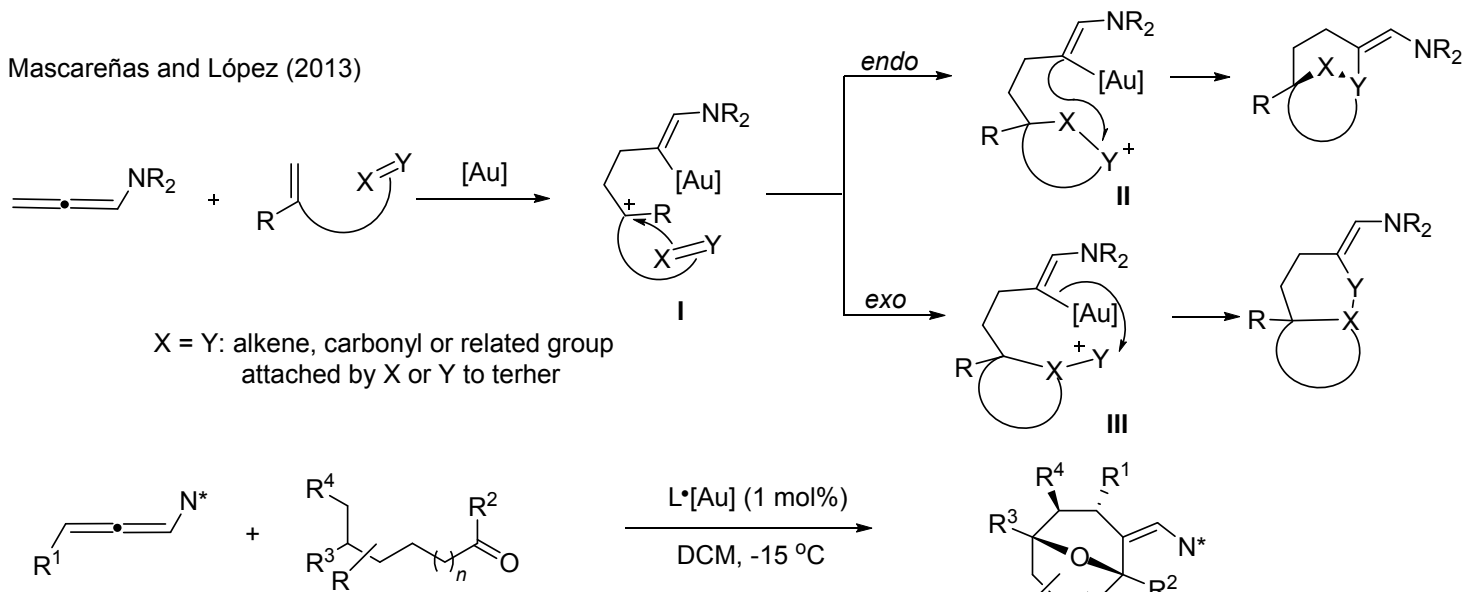

124

$$
\underset{\mathrm{DCM},-15^{\circ} \mathrm{C}}{\stackrel{\mathrm{L}^{\circ}[\mathrm{Au}](1 \mathrm{~mol} \%)}{\longrightarrow}}
$$

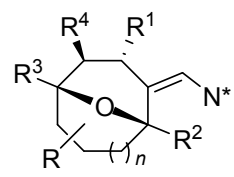

125

Mascareñas and López (2015)

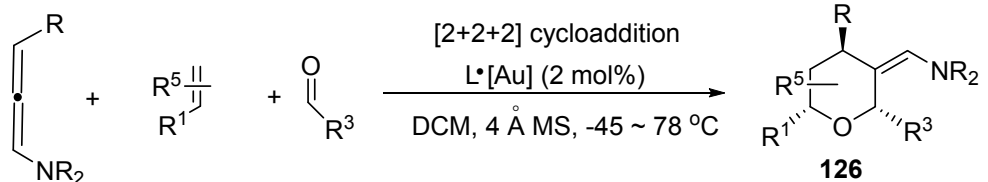

Mascareñas and López (2017)

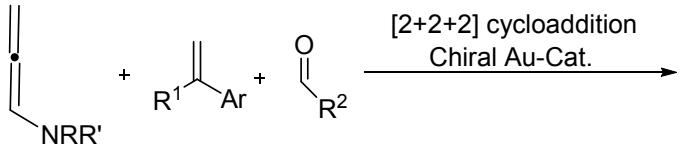

$\mathrm{RR}^{\prime}=$ NTsPh or 2-oxazolidinone
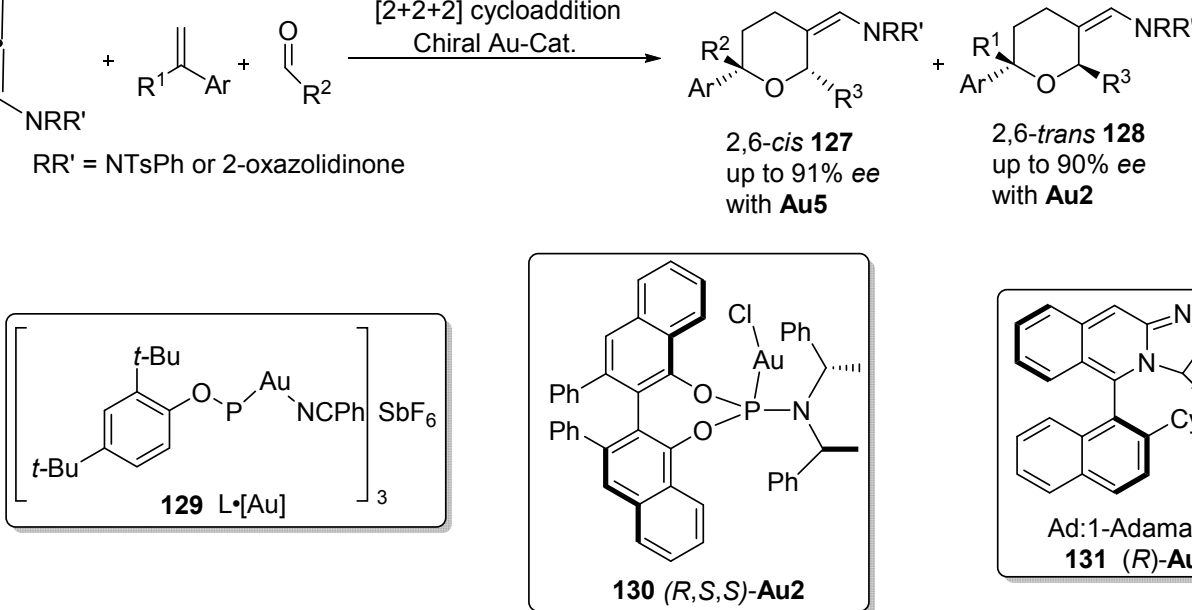

图式 43 金催化新型多组分环加成反应

Scheme 43 Au-catalyzed novel multicomponent cycloaddition reaction<smiles>[R4]C=C=CN([R])[R]</smiles>

$\mathrm{R}^{3}$

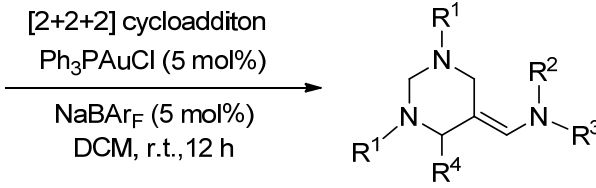

132<smiles>CS(=O)(=O)N(C=C1CN(Cc2ccccc2)CN(Cc2ccccc2)C1)c1ccccc1</smiles>

132a $92 \%$<smiles>FN(C=C1CN(Cc2ccccc2)CN(Cc2ccccc2)C1)c1ccccc1</smiles>

132b $90 \%$<smiles>C[R6](C)(C)OC(C)(C)C</smiles>

132c $85 \%$

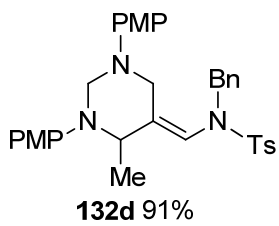

图式 44 金催化 $[2+2+2]$ 环加成反应

Scheme 44 Au catalyzed $[2+2+2]$ cycloaddition 

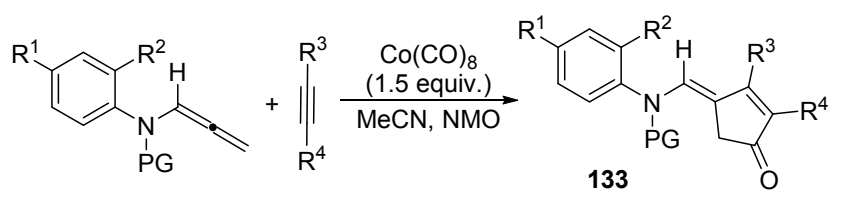<smiles>COc1ccc(N(C=C2CC(=O)C=C2CC(C)(C)C)CC(C)(C)C)cc1</smiles><smiles>CCC1=C(CC)/C(=C/N(CC(C)(C)C)c2ccc(OC)cc2)CC1=O</smiles><smiles>[3H]N(C=C1CC(=O)C(CC)=C1CC)c1ccc(OC)cc1</smiles><smiles>C=Cc1ccccc1N(C=C1CC(=O)C(CC)=C1CC)C(C)(C)C</smiles>

图式 45 钴催化联烯胺分子间环化反应

Scheme 45 Co-catalyzed allenamides intermolecular cyclization

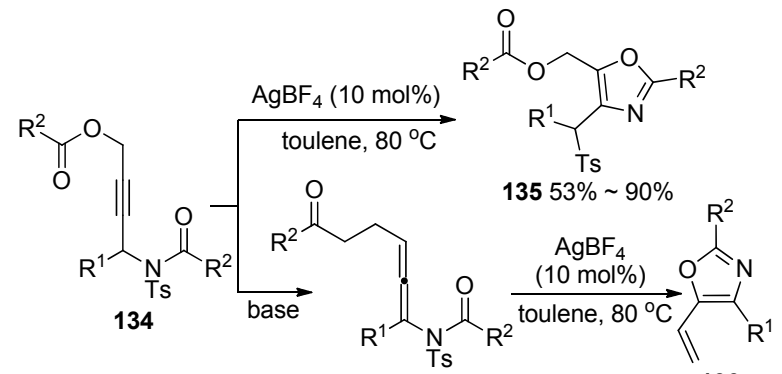

136

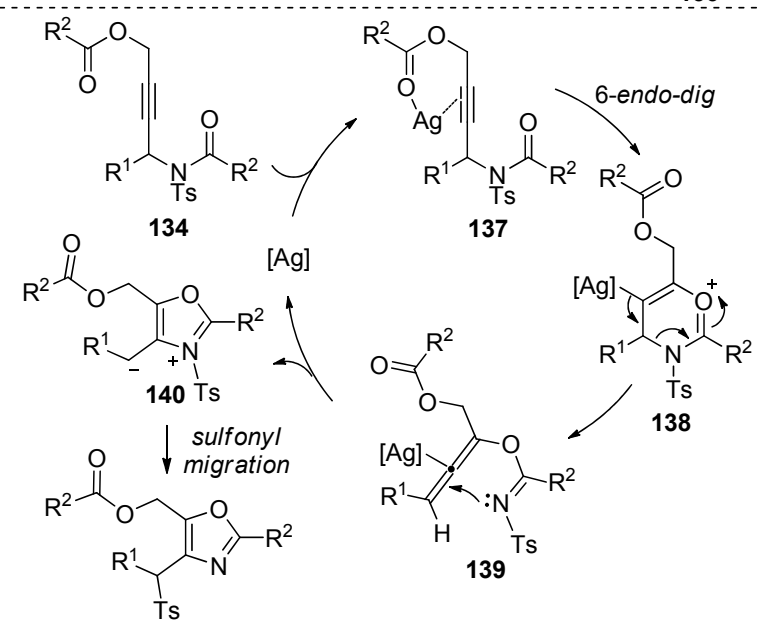

135

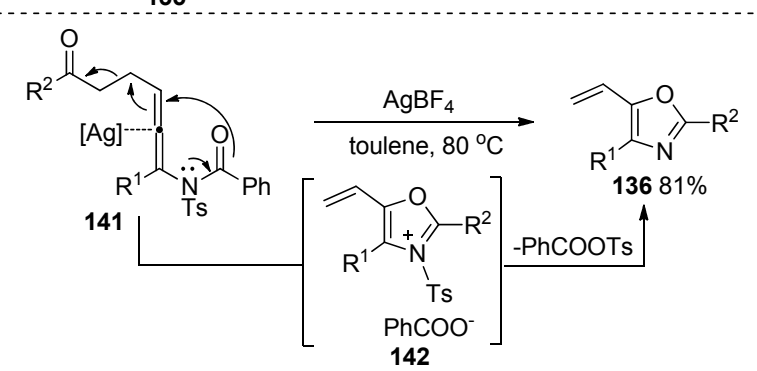

图式 46 银催化联烯胺活化脱羧环化反应

Scheme 46 Ag-catalyzed allenamides activation decarboxylation cyclization
子分子内亲核攻击后环化，磺酰基和酰氧基两者的消除 产生最终的乙烯基啞唑产物 136, 由于这一独有的特征, 该反应为合成乙烯基啞唑提供了一种可行的替代方案.

同年, Crossy 课题组 ${ }^{[60]}$ 实现了银催化的联烯胺环化 合成 3-吡咯啉(Scheme 47). 首先, $N$-Boc 保护的炔丙基 酯 143 在碳酸钾以及碘甲烷的存在下, 完成 EnolateClaisen 重排, 得到 $\gamma$ 取代的联烯胺化合物 144. 接着在 $\mathrm{Ag}$ 的催化下分子内环化, 高区域选择性地得到环戊烯 化合物 145. 作者认为, 该方法实现了立体选择性的功 能化联烯胺的合成, 并且在 $\mathrm{Ag}$ 的催化下可以成为合成 吡咯烷行之有效的方法.

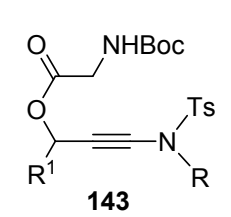

$\underset{\mathrm{AgNO}_{3}(5 \mathrm{~mol} \%)}{\text { acetone, r.t. }}$

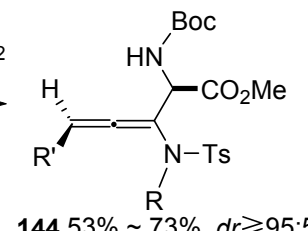

$14453 \% \sim 73 \%, d r \geqslant 95: 5$

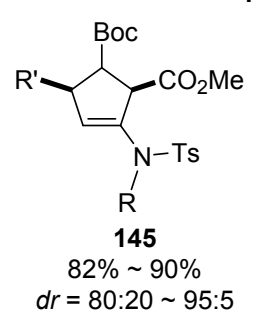

图式 47 Enolate-Claisen 重排制备联烯胺及其环化反应 Scheme 47 Enolate-Claisen rearrangement for allenamides cyclization

\section{Pt 催化联烯胺环化反应}

2017 年, Patil 课题组 ${ }^{[61]}$ 首次报道了 Pt 催化联烯胺与 亚胺炔基化合物间的 $[3+2]$ 环化反应(Scheme 48), 实现 了联烯胺 $\gamma$ 位碳选择性环化，通过该方法可以制备一系 列吡咯[1,2- $a$ ] 吲哚化合物. 作者同样对反应机理进行了 探讨, 首先完成的是 Pt 对炔烃的活化, 亚胺捕获产生甲 亚胺叶立德，接受联烯胺的进攻，接下来, Pt(II)以 1,4方式将电子密度贡献给缺电子亚胺离子以产生 148, 一 旦产生中间体 148, 将发生 1,2-芳基迁移以形成中间体 149, 最后还原消除完成 Pt 催化剂的再生, 得到吡咯 [1,2- $a]$ 吲哚化合物 $\mathbf{1 5 0}$.

\section{$8 \mathrm{Ni}$ 催化联烯胺环化反应}

2017 年, 贾义霞课题组 ${ }^{[62]}$ 首次实现了 $\mathrm{Ni}$ 催化联烯 胺与亚胺的 $[2+2]$ 环加成(Scheme 49), 高对应选择性地 生成含季碳中心的四元含氮杂环化合物. 该转化是在手 性噁唑啉配体的调控下完成的，作者为该反应拟定了可 能的机理. 首先, 底物 151 在手性 $\mathrm{Ni}$ 催化剂的作用下以 


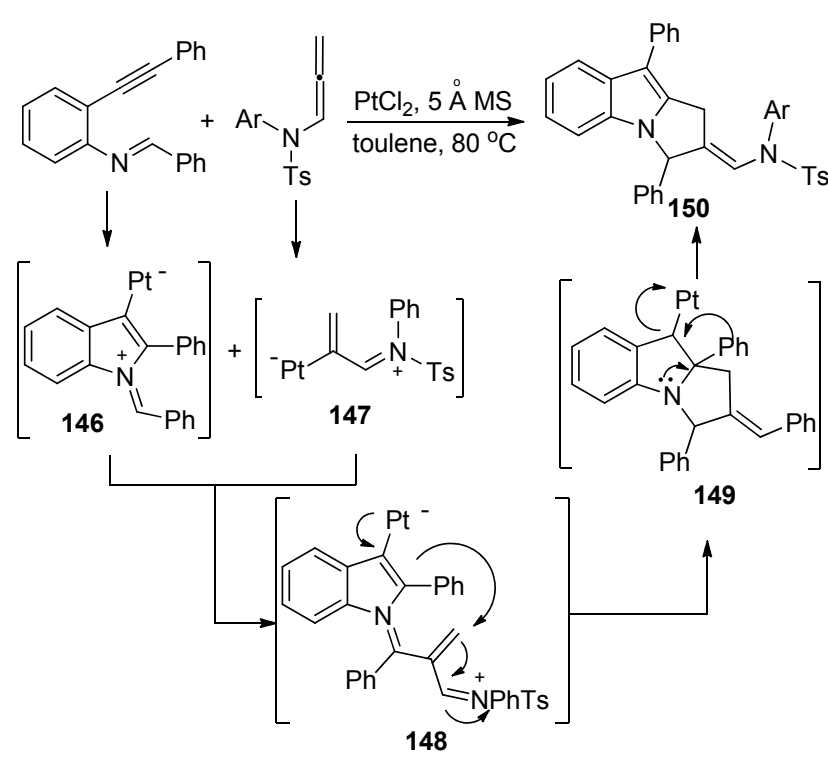

图式 48 铂催化联烯胺与亚胺炔基化合物间的 $[3+2]$ 环化反 应

Scheme 48 Pt-catalyzed [3+2] cyclization reaction between allenamides and iminoalkynyl compounds

1,4-结合的方式活化得到中间体 154, 随后对联烯胺选 择性亲核加成生成 $\mathrm{N}$ 正离子亚胺中间体 155 , 然后亚胺 结构中的碳接收亲核试剂的进攻, 通过区域选择性的分 子内环化, 得到[2+2]环加成产物 152 (Path a). Path b 中 丙烯醛 153 并不是环加成的产物, 可能是由于使用 $N$ 烯丙基噁唑烷酮作为反应底物时，中间体 155 发生水解. 该[2+2]环加成催化循环的实现, 完善了 $\mathrm{Ni}$ 催化联烯胺 环化方法学, 能够高效合成带有四元立体构型中心的多 取代手性氮杂环丁烷骨架分子, 同时具有优异的对映选 择性.

\section{9 结论与展望}

联烯胺类化合物独特的反应特点，使其在钯、钉、 铑、金、钴、银、铂、镍金属催化剂作用下都能高效地 选择性地进行环化反应. 在不同的碱性环境、配体和溶 剂等的影响下, 能够构建不同种类的含有氮原子的杂环 化合物. 因此, 该联烯胺环化反应在现代药物和天然产 物全合成, 以及精细化工合成中都具有非常大的潜在应 用价值. 联烯胺类化合物具有独特的化学反应性和选择 性，通过改变胺的保护基团可以调控氮原子的电子云密 度，在合适的催化剂和配体作用下，对不同选择性的反 应位点进行环化, 从而构建不同原子数的环化产物. 目 前, 在联烯胺类化合物环化反应中, 对反应区域选择性 的探索并不完善, 还有待化学工作者继续探索, 此外, 在联烯胺环化反应中实现可控的手性碳原子构建也是 亟待解决的研究课题. 在此, 希望该综述能为化学工作 者提供帮助, 促进联烯胺环化领域的发展, 研究出更多

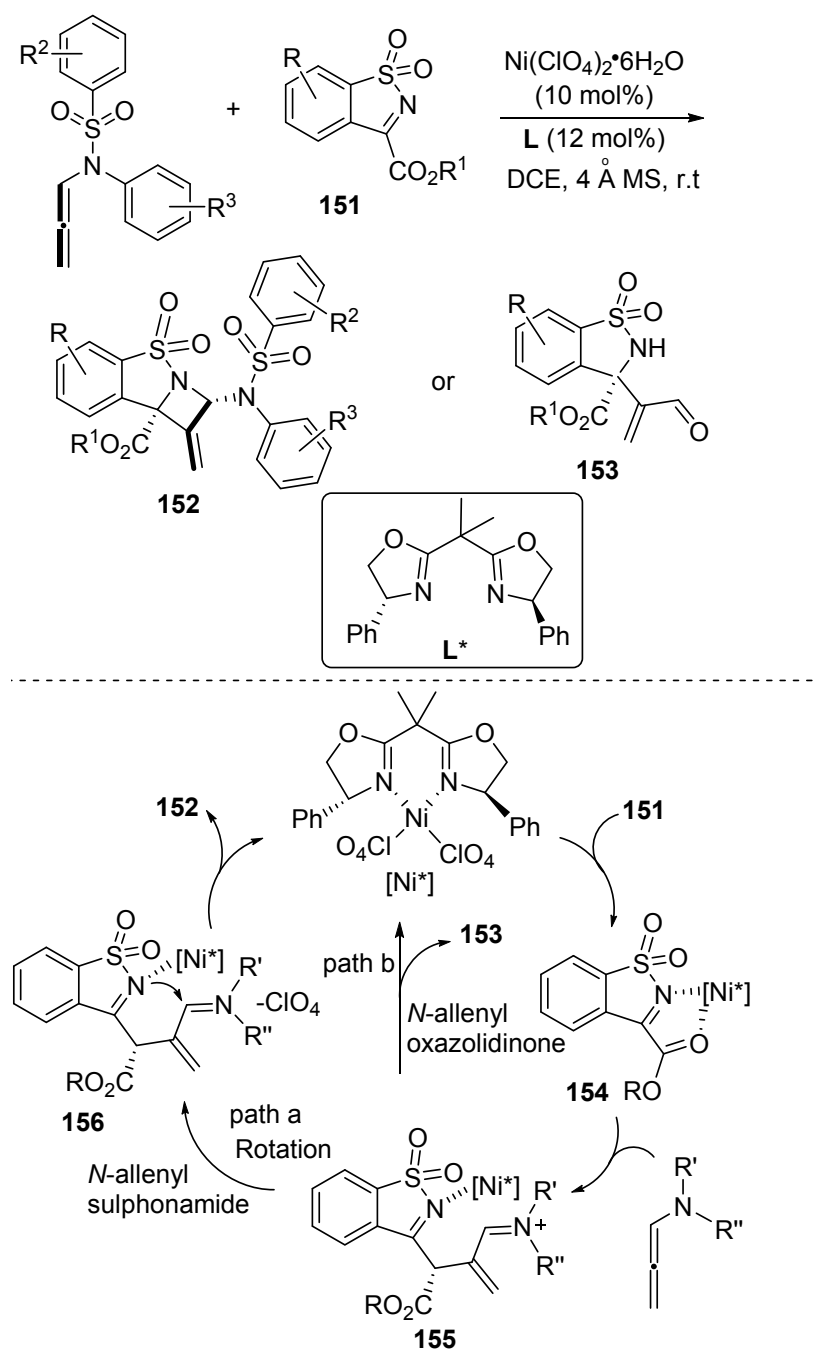

图式 49 镍催化联烯胺 $[2+2]$ 环加成反应

Scheme 49 Ni-catalyzed [2+2] cycloaddition reaction of allenamides

新颖优异的方法.

\section{References}

[1] (a) Colacot, T. New Trends in Cross Coupling: Theory and Applications, RSC, Cambridge, UK, 2015.

(b) Meijere, A.; Oestreich, M. Metal-Catalyzed Cross-Coupling Reactions and More, Wiley-VCH, Weinheim, Germany, 2014.

(c) Hao, E.; Jiang, X.; Fu, D.; Wang, D.; Xie, M.; Qu, G.; Guo, H. Chin. J. Org. Chem. 2016, 36, 2746 (in Chinese).

(郝二军, 蒋小涵, 付丹丹，王东超，谢明胜，渠桂荣，郭海明， 有机化学, 2016, 36, 2746.)

(d) Liu, C.; Liu, G.; Zhao, H. Chin. J. Chem. 2016, 34, 1048.

(e) Dong, X.; Hou, Y.; Meng, F.; Liu, H.; Liu, H. Chin. J. Org. Chem. 2017, 37, 1088 (in Chinese).

(董旭，侯永正，孟凡威，刘洪波，刘会，有机化学， 2017，37, 1088.)

(f) Tang, H. M.; Huo, X. H.; Meng, Q. H.; Zhang, W. B. Acta Chim. Sinica 2016, 74, 219 (in Chinese).

(汤淏溟, 霍小红, 孟庆华, 张万斌, 化学学报, 2016, 74, 219.)

[2] Grigg, R. Sridharan, V. Xu, L.-H. J. Chem. Soc., Chem. Commun. 1995, 1903.

[3] Grigg, R.; Köppen, I.; Rasparini, M.; Sridharan, V. Chem. Commun. 2001, 96. 
[4] Grigg, R.; McCaffrey, S.; Sridharan, V.; Fishwick, C. W. G.; Kilner, C.; Korn, S.; Bailey, K.; Blacker, J. Tetrahedron 2006, 62, 12159.

[5] Inamoto, K.; Yamamoto, A.; Ohsawa, K.; Hiroya, K.; Sakamoto, T. Chem. Pharm. Bull. 2005, 53, 1502.

[6] Husinec, S.; Petkovic, M.; Savic, V.; Simic, M. Synthesis 2012, 44, 399.

[7] Xie, Z.; Wu, P.; Cai, L.; Tong, X. Tetrahedron Lett. 2014, 55, 2160.

[8] Yan, F.; Liang, H,; Song, J.; Cui, J.; Liu, Q.; Liu, S.; Wang, P.; Dong, Y.; Liu, H. Org. Lett. 2017, 19, 86.

[9] Beccalli, E. M.; Bernasconi, A.; Borsini, E.; Broggini, G.; Rigamonti, M.; Zecchi, G. J. Org. Chem. 2010, 75, 6923

[10] Grigg, R.; Loganathan, V.; Sridharan, V.; Stevenson, P.; Sukirthalingam, S.; Worakun, T. Tetrahedron 1996, 52, 11479.

[11] Gardiner, M.; Grigg, R.; Sridharan, V.; Vicker, N. Tetrahedron Lett. 1998, 39, 435.

[12] Fuwa, H.; Sasaki, M. Org. Biomol. Chem. 2007, 5, 2214

[13] Grigg, R.; Sansano, J. M. Tetrahedron 1996, 52, 13441.

[14] Parthasarathy, K.; Jeganmohan, M.; Cheng, C. Org. Lett. 2006, 8, 621.

[15] Cao, J.; Kong, Y.; Deng, Y.; Lai, G.; Cui, Y.; Hu, Z.; Wang, G. Org. Biomol. Chem. 2012, 10, 9556.

[16] Grigg, R.; Sansano, J. M.; Santhakumar, V.; Sridharan, V.; Thangavelanthum, R.; Thornton-Pett, M.; Wilson, D. Tetrahedron 1997, 53, 11803.

[17] Fuwa, H.; Sasaki, M. Org. Biomol. Chem. 2007, 5, 2214.

[18] Liang, H.; Yan, F.; Dong, X.; Liu, Q.; Wei, X.; Liu, S.; Dong, Y.; Liu, H. Chem. Commun. 2017, 53, 3138.

[19] Zhu, S.; Cao, J.; Wu, L.; Huang, X. J. Org. Chem. 2012, 77, 1049.

[20] (a) Zhu, C.; Yang, B.; Jiang, T.; Bäckvall, J.-E. Angew. Chem., Int. Ed. 2015, 54, 9066

(b) Qiu, Y.; Yang, B.; Zhu, C.; Bäckvall, J.-E. Angew. Chem., Int. Ed. 2016, 128, 6630.

[21] Persson, A. K. Å.; Bäckvall, J.-E. Angew. Chem., Int. Ed. 2010, 49, 4624.

[22] (a) Arisawa, M.; Terada, Y.; Takahashi, K.; Nakagawa, M.; Nishida, A. J. Org. Chem. 2006, 71, 4255.

(b) Donohoe, T. J.; O'Riordan, T. J. C.; Rosa, C. P. Angew. Chem., Int. Ed. 2009, 48, 1014

[23] Poeylaut-Palena, A. A.; Testero, S. A.; Mata, E. G. Chem. Commun. 2011, 47, 1565

[24] Edlin, C. D.; Faulkner, J.; Quayle, P. Tetrahedron Lett. 2006, 47, 1145 .

[25] Bokka, A.; Hua, Y.; Berlin, A. S.; Jeon, J. ACS Catal. 2015, 5, 3189.

[26] (a) Kim, B. G.; Snapper, M. L. J. Am. Chem. Soc. 2006, 128, 52. (b) Peppers, B. P.; Diver, S. T. J. Am. Chem. Soc. 2004, 126, 9524.

[27] Zeng, X.; Wei, Z.; Farina, V.; Napolitano, E.; Xu, Y.; Zhang, L.; Haddad, N.; Yee, N. K.; Grinberg, N.; Shen, S.; Senanayake, C. H. J. Org. Chem. 2006, 71, 8864 .

[28] Dornan, P. K.; Wickens, Z. K.; Grubbs, R. H. Angew. Chem., Int. Ed. 2015, 54, 7134 .

[29] Gavenonis, J.; Arroyo, R. V.; Snapper, M. L. Chem. Commun. 2010, 46, 5692.

[30] (a) Rosillo, M.; Casarrubios, L.; Domínguez, G.; Pérez-Castells, J. Tetrahedron Lett. 2001, 42, 7029.

(b) Rosillo, M.; Domínguez, G.; Casarrubios, L.; Amador, U.; Pérez-Castells, J. J. Org. Chem. 2004, 69, 2084.

[31] (a) López, F.; Delgado, A.; Rodríguez, J. R.; Castedo, L.; Mascareñas, J. L. J. Am. Chem. Soc. 2004, 126, 10262.

(b) Arisawa, M.; Fujii, Y.; Kato, H.; Fukuda, H.; Matsumoto, T.; Ito,
M.; Abe, H.; Ito, Y.; Shuto, S. Angew. Chem., Int. Ed. 2013, 52 1003.

[32] Desroy, N.; Robert-Peillard, F.; Toueg, J.; Hénaut, C.; Duboc, R. Rager, M.-N.; Savignac, M.; Gênet, J.-P. Synthesis 2004, 2665.

[33] Kinderman, S. S.; Van Maarseveen, J. H.; Schoemaker, H. E.; Hiemstra, H.; Rutjes, F. P. T. Org. Lett. 2001, 3, 2045.

[34] Nada, T.; Yoneshige, Y.; Ii, Y.; Matsumoto, T.; Fujioka, H.; Shuto, S.; Arisawa, M. ACS Catal. 2016, 6, 3168.

[35] Barluenga, J.; Vicente, R.; López, L. A.; Tomás. M. J. Am. Chem. Soc. 2006, 128, 7050 .

[36] Brummond, K. M.; Yan, B. Synlett 2008, 2303.

[37] Lindsay, V. N. G.; Fiset, D.; Gritsch, P. J.; Azzi, S.; Charette, A. B. J. Am. Chem. Soc. 2013, 135, 1463.

[38] Zheng, W.; Bora, P. P.; Sun, G.; Kang. Q. Org. Lett. 2016, 18, 3694.

[39] Lin, T.; Zhu, C.; Zhang, P.; Wang, Y.; Wu, H.; Feng, J.; Zhang, J. Angew. Chem., Int. Ed. 2016, 55, 10844.

[40] Hyland, C. J. T.; Hegedus, L. S. J. Org. Chem. 2006, 71, 8658.

[41] Watanabe, T.; Oishi, S.; Fujii, N.; Ohno, H. Org. Lett. 2007, 9, 4821.

[42] González-Gómez, A.; Domínguez, G.; Pérez-Castells, J. Eur. J. Org. Chem. 2009, 5057.

[43] Ma, Z.; He, S.; Song, W.; Hsung, R. P. Org. Lett. 2012, 14, 5736.

[44] Li, X.; Zhu, L.; Zhou, W.; Chen. Z. Org. Lett. 2012, 14, 436.

[45] Faustino, H.; Bernal, P.; Castedo, L.; López, F.; Mascareñas, J. L. Adv. Synth. Catal. 2012, 354, 1658.

[46] Suarez-Pantiga, S.; Hernández-Díaz, C.; Piedrafita, M.; Rubio, E.; Gonzáleza, J. M. Adv Synth. Catal. 2012, 354, 1651.

[47] Ocello, R.; Nisi, A. D.; Jia, M.; Yang, Q.; Monari, M.; Giacinto, P.; Bottoni, A.; Miscione, G. P.; Bandini. M. Chem. Eur. J. 2015, 21, 18445.

[48] Li, G.; Zhou, E.; Li, X.; Bi, Q.; Wang, Z.; Zhao, Z.; Hu, W.; Chen, Z. Chem. Commun. 2013, 49, 4770 .

[49] Wang, Y.; Zhang, P.; Qian, D.; Zhang, J. Angew. Chem., Int. Ed. 2015, 54, 14849 .

[50] Singh, R. R.; Pawar, S. K.; Huang, M.; Liu, R. Chem. Commun 2016, 52, 11434.

[51] Faustino, H.; López, F.; Castedo, L.; Mascareñas, J. L. Chem. Sci. 2011, 2, 633 .

[52] Francos, J.; Grande-Carmona, F.; Faustino, H.; Iglesias-Sigüenza, J.; Díez, E.; Alonso, I.; Fernández, R.; Lassaletta, J. M.; López, F.; Mascareñas, J. L. J. Am. Chem. Soc. 2012, 134, 14322.

[53] Pirovano, V.; Decataldo, L.; Rossi, E.; Vicente, R. Chem. Commun 2013, 49, 3594.

[54] Faustino, H.; Alonso, I.; Mascareñas, J. L.; López, F. Angew. Chem., Int. Ed. 2013, 52, 6526.

[55] Faustino, H.; Varela, I.; Mascareñas, J. L.; López, F. Chem. Sci. 2015, 6, 2903.

[56] Varela, I.; Faustino, H.; Díez, E.; Iglesias-Sigüenza, J.; GrandeCarmona, F.; Fernandez, R.; Lassaletta, J. M.; Mascareñas, J. L.; López. F. ACS Catal. 2017, 7, 2397.

[57] Peng, S.; Cao, S.; Sun, J. Org. Lett. 2017, 19, 524

[58] Anorbe, L.; Poblador, A.; Domínguez, G.; Pérez-Castells, J. Tetrahedron Lett. 2004, 45, 4441.

[59] Hu, Y.; Yi, R.; Wu, F.; Wan, B. J. Org. Chem. 2013, 78, 7714.

[60] Brioche, J.; Meyer, C.; Cossy, J. Org. Lett. 2013, 15, 1626.

[61] Chakrabarty, I.; Inamdar, S. M.; Akram, M. O.; Gade, A. B.; Banerjee, S.; Berac, S.; Patil, N. T. Chem. Commun. 2017, 53, 196.

[62] Liu, R.; Hu, J.; Hong, J.; Lu, C.; Gao, J.; Jia, Y. Chem. Sci. 2017, 8, 2811.

$(\mathrm{Lu}, \mathrm{Y}$.) 